\title{
Layer inflow into precipitating convection over the western tropical Pacific
}

\author{
By DAVID B. MECHEM ${ }^{1 *}$, ROBERT A. HOUZE Jr ${ }^{1}$ and SHUYI S. CHEN ${ }^{2}$ \\ ${ }^{1}$ University of Washington, USA \\ ${ }^{2}$ University of Miami, USA
}

(Received 29 January 2001; revised 19 November 2001)

\begin{abstract}
SUMMARY
A conceptual model of tropical convection frequently used in convective parametrization schemes is that of a parcel process in which boundary-layer air, characterized by high equivalent potential temperature, ascends to great heights in convective updraughts, while air above the planetary boundary layer with lower equivalent potential temperature mixes into convective downdraughts and sinks. However, airborne Doppler-radar data show that organized deep convective systems over the western tropical Pacific warm pool are often characterized by layers of ascending inflow $\sim 0.5-4 \mathrm{~km}$ in depth. These inflow layers do not consist merely of boundary-layer air.

In this study a high-resolution numerical cloud model is employed to investigate these inflow layers. Input data are from the Tropical Ocean-Global Atmosphere Coupled Ocean-Atmosphere Response Experiment (TOGA COARE). Two time periods are selected in December 1992, which represent the onset and peak of a strong westerly phase of the intraseasonal oscillation. Model simulations for 14 December, representative of westerly onset conditions and the beginning of a convectively active period, and 23 December, representative of strong low-level westerlies and extremely widespread convection, are conducted. To bridge the coarse resolution of the global-model analysis fields and the fine resolution of the cloud model, hourly output from a mesoscale model is used to supply initial and lateral boundary conditions for the cloud model.

Control simulations of 14 and 23 December reveal distinct convective organizations and, specifically, inflow characteristics for the two systems embedded in different large-scale environmental conditions. In the case of 23 December, convection simulated under conditions of the strong westerly wind and near-saturated low-mid troposphere exhibits deep inflow layers. Trajectories computed from the simulation of 23 December under these conditions show a strong layer-lifting inflow signal. In contrast, the control simulation of 14 December shows a parcel-like inflow with only the air in the lower part of the inflow actually rising in the deep convective updraughts. One of the main differences between the two simulations is the lack of a deep environmental moist layer in the 14 December case. The control simulation did not capture well the extent of precipitating mesoscale stratiform clouds that developed from earlier convection in the vicinity of the deep convective cells as indicated in the COARE observations. Previous studies have shown that spatially extensive convection is correlated with enhanced mid-level humidity. To isolate the effect of the mid-level moist layer on the characteristics of inflow of convective systems, a numerical experiment based on the control simulation of 14 December was conducted. The relative humidity of environment air in the low-mid troposphere (1.7-6 km layer) was increased to 95\%. Trajectory statistics calculated for this sensitivity experiment show increased layer lifting, with a significant amount of air from the upper part of the inflow layer rising in the updraught along with air from just above the surface. Moistening the inflow layer in this sensitivity experiment allows it to saturate more quickly when it encounters the mesoscale cold pool. Once saturated, the relevant static stability is the moist rather than dry static stability, and the whole layer more easily rises over the cold pool. Moistening the inflow layer also modifies the nature of the simulated cold pool itself, which seems to promote layer lifting in the simulation. Possible mechanisms for moistening the mid-levels are briefly discussed.
\end{abstract}

KEYWORDS: Mesoscale convective systems Thermodynamics Warm pool

\section{INTRODUCTION}

Convective organization over the western Pacific warm pool varies with the largescale environmental conditions as described by Houze et al. (2000). One particular aspect of convective organization is the characteristic of the inflow into convective systems. Kingsmill and Houze (1999) used aircraft Doppler-radar data obtained over the western Pacific warm pool during TOGA COARE $\dagger$ to show that deep mesoscale convective systems (MCSs) over that region have layers of inflow feeding sloping updraughts, and that these inflow layers are not simply composed of boundary-layer air but rather are typically $\sim 0.5-4 \mathrm{~km}$ in depth. Recently, Bryan and Fritsch (2000)

* Corresponding author: Cooperative Institute for Mesoscale Meteorological Studies, University of Oklahoma, 100 E. Boyd, Rm 1110, Norman, OK 73019-1011, USA. e-mail: dmechem@ ou.edu

$\dagger$ The Tropical Ocean-Global Atmosphere Coupled Ocean-Atmosphere Response Experiment.

(C) Royal Meteorological Society, 2002. 
have called attention to layer lifting in mid-latitude MCSs. Their finding suggests a fundamental similarity between mid-latitude MCSs and tropical cloud systems observed in the western Pacific warm pool. Our study seeks to understand layer lifting in convection over the warm pool.

The existence of layer lifting in major convective clouds over the warm pool appears paradoxical since equivalent potential temperature $\left(\theta_{\mathrm{e}}\right)$ and relative humidity of the ambient environment decrease with height in this layer. For this reason it has been previously thought that the air in the upper part of the inflow layer sinks, and only the boundary-layer air in the lower part of the inflow layer actually rises in the deep convective updraughts. Betts (1976) and Zipser (1977) advocated the concept of a 'crossover zone' in the leading portion of an isolated tropical Atlantic squall line. Twodimensional projections of trajectories of the sinking air from the upper part of the inflow layer crosses over the two-dimensional projections of trajectories of the air rising from the lower part of the boundary layer. A spectrum of mixing was implied in which parcels from low levels tend to become buoyant cores, while air parcels in the upper part of the inflow layer which entrain the smallest amount of high $-\theta_{\mathrm{e}}$ air while passing through the crossover zone sink to the surface, with the thermodynamic assistance of evaporation of rain and cloud droplets (Zipser 1977). Redelsperger and Lafore's (1988) simulations of a tropical West African squall line supported the crossover-zone idea. They showed two distinctly different air masses crossing each other between $1.5 \mathrm{~km}$ and $5 \mathrm{~km}$ in height, and that this crossing occurred at the convective scale and involved similar-sized pockets of high and low $\theta_{\mathrm{e}}$.

Since tropical deep convection is an important element of the global oceanatmosphere climate system (Webster 1994), a correct understanding of convection is prerequisite to its accurate portrayal in global climate models. Most cumulus parametrization schemes in current use are based on entraining plume or bubble models with parcel theory underpinnings, with the atmospheric boundary layer being the focus of this perspective (Emanuel and Raymond 1993). The $\theta_{\mathrm{e}}$ of these parcels is modified by surface fluxes across the ocean-atmosphere interface, and parcels of high $\theta_{\mathrm{e}}$ ascend until decelerated by entrainment or a stable layer. Downdraughts of lower $\theta_{\mathrm{e}}$ descend into the boundary layer where the air may be modified by surface fluxes. This view is consistent with the crossover-zone idea.

The overall validity of a parametrization based on the assumption of parcels rising out of and sinking into the boundary layer depends further upon the extent to which the subgrid scale is in statistical equilibrium with the resolved system (Emanuel 1994). The notion of statistical equilibrium rests upon the idea that the temporal scale of the small-scale processes is significantly smaller than that of the resolved scale such that there is a separation of scale between the two. When MCSs reach horizontal scales of hundreds of kilometres and take on stratiform components (Zipser 1969, 1977; Maddox 1980; Chen et al. 1996; Kingsmill and Houze 1999; Houze et al. 2000), the failure of the scale-separation assumption becomes possible, if not likely.

In this paper we will argue that the parcel view (as expressed by Betts (1976), Zipser (1977), and Redelsperger and Lafore (1988)) is most applicable when a dry mid-level layer is present, while layer lifting better describes the nature of inflow when the midlevels are moistened. The parcel view would be more applicable to the early stages of an MCS, while layer lifting better describes the later, more mature stages of the system, when a large region of stratiform cloud and precipitation is likely present (Bryan and Fritsch 2000). To make this case, we will use model calculations to trace air parcels into and through storms such as were observed over the western Pacific warm pool during the TOGA COARE. 


\section{Methodology}

\section{(a) The ARPS cloud model}

This study is based on the Advanced Regional Prediction System (ARPS) version 4.2.3a cloud model (Xue et al. 1995). ARPS is fully compressible and formulated in a generalized terrain-following coordinate system. It uses grid stretching in the vertical, which resolves accurately the characteristically thin tropical (COARE) boundary-layer cold pools. Vertical grid spacing ranges from $200 \mathrm{~m}$ at the surface to $1000 \mathrm{~m}$ aloft. A 1.5-order turbulent kinetic energy(TKE)-based closure scheme parametrizes subgridscale processes. A prognostic equation for the TKE equation is solved, and the TKE is related to the turbulent mixing coefficients. This scheme allows for countergradient mixing, a process that occurs in organized tropical convection (LeMone et al. 1984). A rigid-top boundary condition is used in combination with a zone of Rayleigh damping to minimize reflection of internal gravity waves.

The model does not include radiative effects or surface fluxes of heat, moisture, and momentum. The rationale for ignoring surface fluxes arises from Trier et al. (1996), who concluded that the only added benefit of including these fluxes is slightly improved representation of the system during a relatively short simulation. Although in that case a squall line was the object of study, we assume that these results generalize to weaker, less organized convection. Radiative effects are ignored in view of the relatively short duration of the simulation. Surface fluxes and radiative effects arise indirectly, through boundary conditions provided by a mesoscale model, as described below.

\section{(b) Initial and boundary conditions}

We initialized the cloud model with the output fields from a mesoscale model. Chen (1997) performed mesoscale model simulations with the fifth generation Penn State/National Center for Atmospheric Research non-hydrostatic, mesoscale model (MM5, see Grell et al. 1994) over the Western Pacific warm-pool region for several consecutive days in middle and late December 1992. MM5 simulations were conducted using a nested grid configuration with 45 and $15 \mathrm{~km}$ grid spacing for the coarse and fine meshes, respectively. For the coarse outer mesh, subgrid-scale convective clouds were parametrized using the Kain-Fritsch (1990) scheme, while both parametrized and explicitly resolved convection were calculated over the fine inner domain. We used a subset of the inner domain high-resolution $(15 \mathrm{~km})$ grid as initial and lateral boundary conditions for cloud-model simulations carried out on a grid of $2 \mathrm{~km}$ horizontal resolution. This approach sacrifices the simplicity of a single-sounding cloud-model experiment; however, it overcomes the constraint of initial horizontal homogeneity often intrinsic to cloud-model simulations. The technique used here is in principle quite similar to the approach used successfully in the Mesoscale Alpine Project (MAP), where the Swiss mesoscale model initialized with the European Centre for Medium-Range Weather Forecasts (ECMWF) analysis field supply the initial and lateral boundary conditions for the high-resolution Canadian MC2 (Modèle Mésoéchelle Compressible Communautaire) for real-time forecasts in the MAP (Bougeault et al. 2001). In this study, MM5 is initialized with a mesoscale analysis field that uses the ECMWF global analysis and additional TOGA COARE soundings and surface observations. The quality of the MM5 simulations is limited by the ECMWF analysis fields and the relative coarseness of the TOGA COARE soundings.

The available input data from the mesoscale model consist of three wind components $(u, v$ and $w)$, temperature, pressure, water vapour, rain water, cloud water and cloud ice. The last two quantities, by definition, have zero terminal fall speed. An ARPS 
external data preprocessor ingests the MM5 fields and interpolates them onto the ARPS grid. A single application of a 9-point filter smoothes the data. The MM5 fields were already reasonably smooth, so they did not require multiple applications of the filter. The vertical velocity is diagnosed from the horizontal wind components of the MM5 via the anelastic continuity equation. The MM5 uses an ice-phase parametrization that allows snow and ice but not mixed-phase hydrometeors. Because of significant differences in the microphysical parametrization scheme, we did not initialize ARPS with the MM5 hydrometeor fields. Although neglecting these fields possibly delays the development of convection, the ARPS hydrometeor fields quickly adjust to the circulation imposed upon them by the mesoscale model.

We employ a relaxation boundary condition in ARPS (Davies 1983) to force the lateral boundaries using the hourly mesoscale model data. This scheme adds a forcing term, calculated by linear interpolation of the hourly supplied MM5 data, to the righthand side of the $u, v, w$, temperature, pressure and water vapour equations in a narrow zone near the lateral boundaries. The forcing is strongest at the boundary and decreases to a fifth of this value at the inner edge of the zone, which gently but firmly forces the boundary solution towards the external value (Xue et al. 1995).

\section{(c) Model microphysics}

The version of ARPS applied in this study employs the commonly used Lin et al. (1983; hereafter LFO) bulk cloud microphysical parametrization, which contains five hydrometeor species: cloud water, rain water, cloud ice and two precipitating ice categories. For tropical convection, McCumber et al. (1991) suggested using the Rutledge and Hobbs (1984) parameters in the LFO scheme. An extension of this approach was developed by Potter (1991) and used by Yang and Houze (1995). This method makes use of Locatelli and Hobbs's (1974) empirical fall-speed relations for various types of solid precipitation particles. Their category 'graupel-like snow of hexagonal type' is used for one of the LFO precipitating ice fields, while 'hexagonal graupel' is used for the other precipitating ice field. As discussed by Potter (1991), the particle diameter used in the derivation of the fall-speed relations represents the diameter of the melted particle and, for consistency, the densities of the ice substances must be changed to the density of liquid water. Following Braun and Houze (1994) we have further modified the microphysical scheme to omit the density-correction term in the snow fall-speed equation.

\section{CONVECTION IN THE STRONG WESTERLy REGION OF THE KELVIN-ROSSBy WAVE}

\section{(a) Environmental conditions of the 23 December case}

Chen et al. (1996) and Godfrey et al. (1998) have described the general atmospheric and convective conditions over the western Pacific warm pool during TOGA COARE (November 1992-February 1993). Two cycles of the Madden and Julian (1971, 1972) intraseasonal oscillation (ISO) affected the warm-pool region during TOGA COARE. Each ISO cycle culminated over the TOGA COARE region in a large-scale KelvinRossby wave pattern with cyclonic gyres on either side of the equator, low-level westerly winds (called westerly wind 'burst'), and extensive convective activity over the TOGA COARE region (Harrison and Giese 1991; Young et al. 1995; Chen et al. 1996; Lin and Johnson 1996; Houze et al. 2000). We focus on December 1992, when some of the most widespread and intense convection of TOGA COARE occurred over the warm pool in association with the onset and peak of a strong westerly wind burst.

The western Pacific warm-pool region in late December of TOGA COARE was characterized by the strong westerly regime of the Kelvin-Rossby wave. This regime 

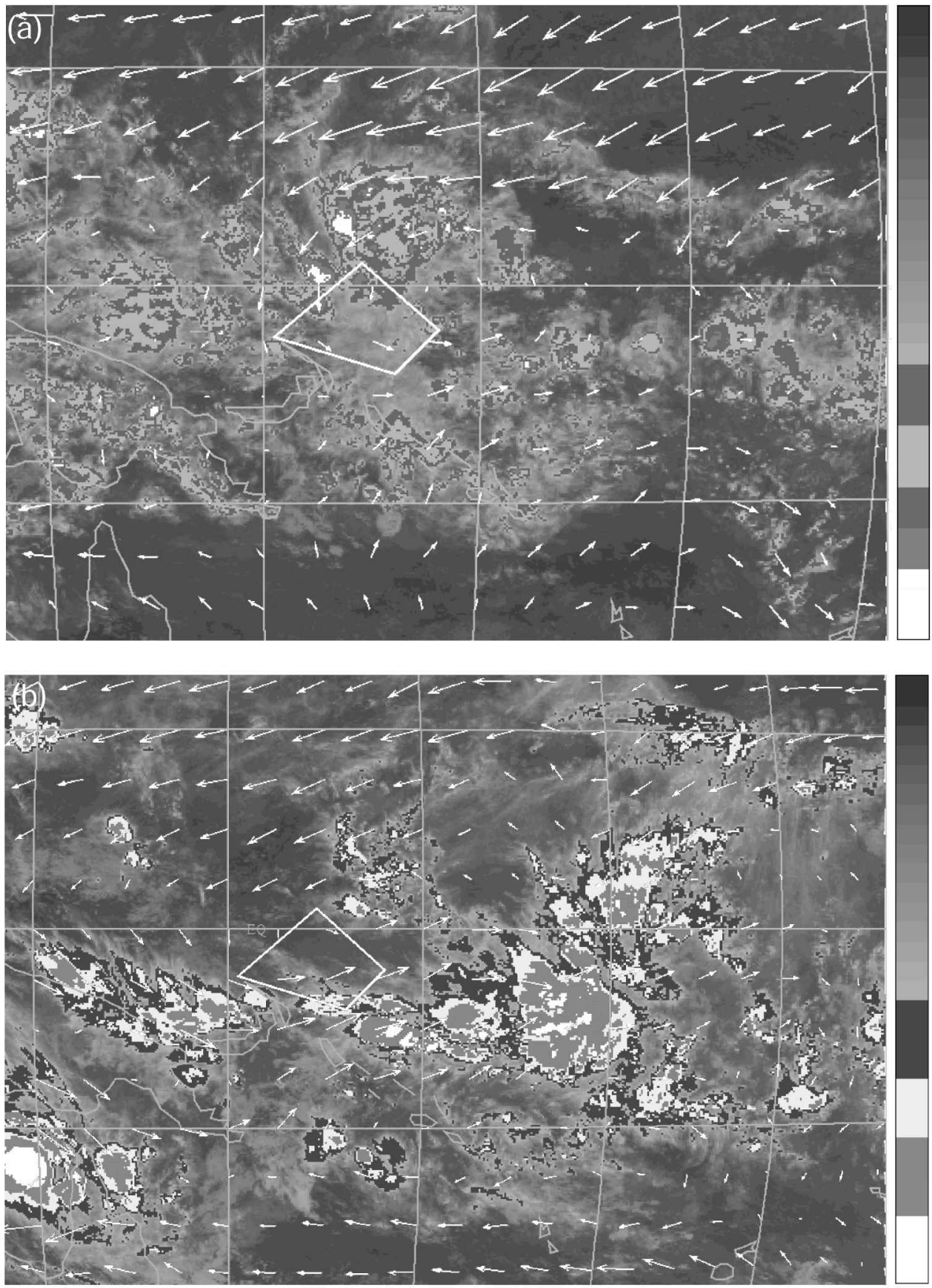

Figure 1. Geostationary Meteorological Satellite infrared imagery and $850 \mathrm{mb}$ ECMWF winds for (a) 0800 UTC 14 December 1992 and (b) 2000 UTC 23 December 1992. The box encloses the TOGA COARE intensive flux array. Wind vectors are plotted every $2.5^{\circ}$ and are scaled such that a $20 \mathrm{~m} \mathrm{~s}^{-1}$ wind is represented by a vector that would be $2.5^{\circ}$ in length on the map at the equator. 
(a)

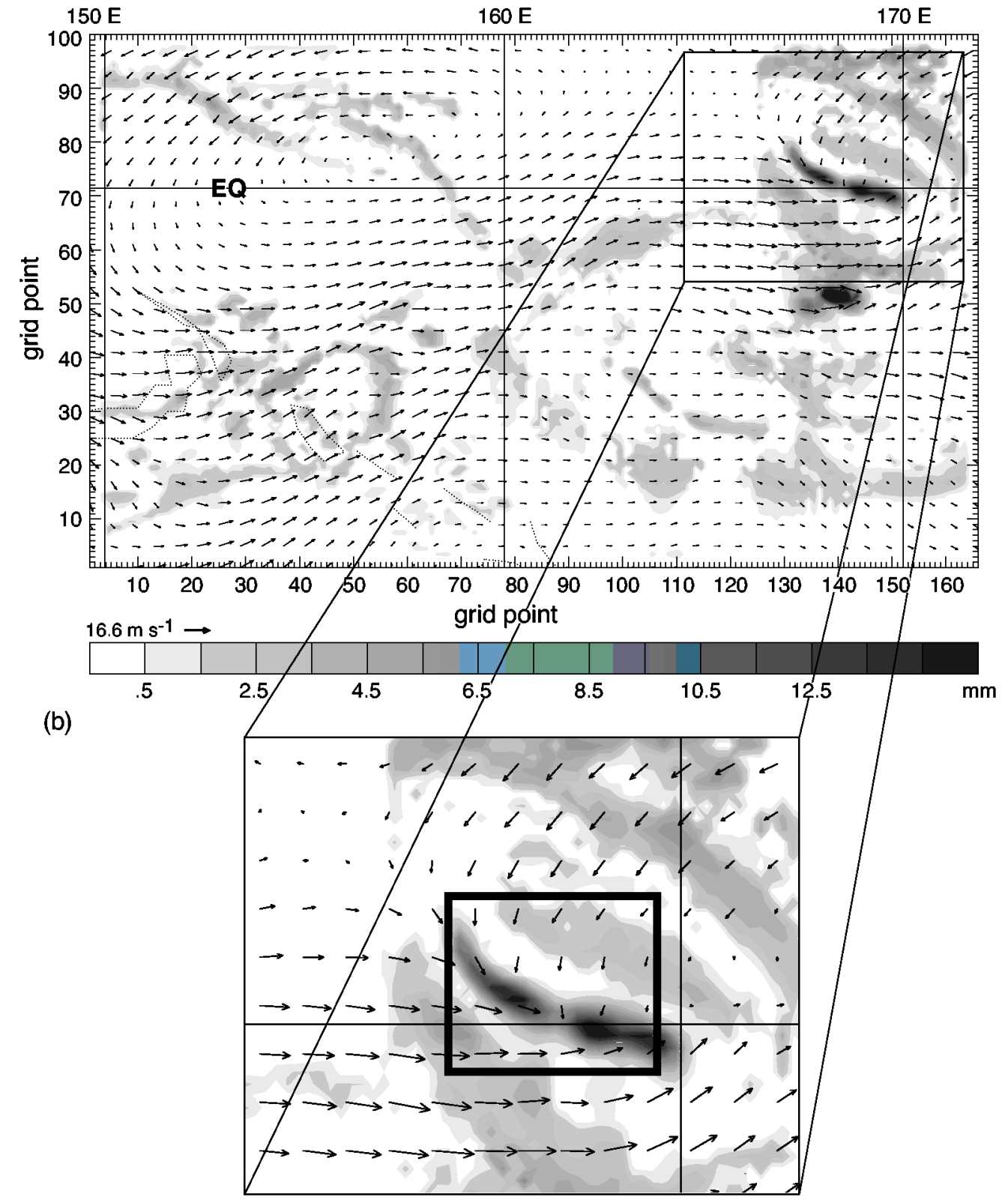

Figure 2. (a) 2000 UTC 23 December 1992 horizontal cross-section of $850 \mathrm{mb}$ wind and hourly accumulated surface rainfall from the $15 \mathrm{~km}$ grid of the MM5 simulation. (b) Magnification of the north-east region of (a). The ARPS (see text) model domain is enclosed by the rectangle centred at $0.4^{\circ} \mathrm{N}, 168.0^{\circ} \mathrm{E}$. 
TABLE 1. CONTROL Simulation Parameters For 14 AND 23 DeCEMber 1992 CASES

\begin{tabular}{ll}
\hline Parameter & Value \\
\hline Domain width (E-W) & $284 \mathrm{~km}$ \\
Domain width (N-S) & $196 \mathrm{~km}$ \\
Domain height & $19.2 \mathrm{~km}$ \\
Horizontal grid spacing & $2 \mathrm{~km}$ \\
Vertical grid spacing (in planetary boundary layer) & $200 \mathrm{~m}$ \\
Vertical grid spacing (average) & $600 \mathrm{~m}$ \\
Time step (large) & $12 \mathrm{~s}$ \\
Time step (small) & $3 \mathrm{~s}$ \\
Length of simulation & $6 \mathrm{~h}$ \\
Initial conditions & Horizontally inhomogeneous values \\
& of horizontal velocity, temperature, \\
& pressure and water vapour supplied \\
Boundary conditions & by MM5 (see text) output data \\
& Linearly interpolated in time from \\
& hourly MM5 velocity, temperature, \\
& pressure and water vapour data \\
\hline
\end{tabular}

was the most convectively active of TOGA COARE (Chen et al. 1996). It was characterized by 'super cluster' conditions (Nakazawa 1988; Mapes and Houze 1993; Chen et al. 1996), with densely packed large MCSs within the region of strong low-level westerly winds (e.g. Fig. 1(b)). This period was dominated by the presence of simultaneous MCSs, often with stratiform regions $\sim 500000-1000000 \mathrm{~km}^{2}$ in horizontal dimensions described as 'super convective systems' by Chen et al. (1996). The extensive and longlasting regions of stratiform precipitation observed during this time period imply a high degree of mesoscale organization that provided ample opportunity to moisten layers of air that could eventually become MCS inflow. The MM5 was initialized at 1200 UTC on 23 December 1992. The coarse-grid version of the MM5 was run over the TOGA COARE large-scale array (LSA) under the strong westerly regime to provide initial and boundary conditions for ARPS. Figure 2(a) shows this region and the low-level strong westerly conditions prevailing at this time. Approximately six hours of spin-up time was required before reasonable initial fields were available, and which could be used by ARPS. MM5 developed an MCS in the north-east corner of the fine-mesh domain with a region of extensive precipitation. Although the MM5 is expected to give only a plausible response to large-scale conditions and not necessarily be a perfect match with observed MCSs, satellite imagery from 23 December shows an extensive coldcloud shield symptomatic of a significant convective event in a location similar to the simulated MCS (cf. Figs. 1(b) and 2(a)). The simulated region of convection formed a few hours before the time shown but well after the spin-up had been accomplished.

\section{(b) The 23 December simulation}

We initialized the ARPS model with MM5 output from a run in which the MM5 was set up with an outer domain of $\sim 5000 \mathrm{~km} \times 2500 \mathrm{~km}$, slightly larger than the LSA, and an inner domain of $\sim 2500 \mathrm{~km} \times 1500 \mathrm{~km}$, which includes the TOGA COARE intensive flux array (see Godfrey et al. (1998) for details of the TOGA COARE observational array). Horizontal grid spacings for the coarse and fine meshes were 45 and $15 \mathrm{~km}$, respectively, and both domains contained 25 vertical levels (Chen 1997).

For this experiment, the ARPS domain is $145 \times 101 \times 35$ points, centred at $0.4^{\circ} \mathrm{N}$ and $168^{\circ} \mathrm{E}$, and the initial conditions are a subset of the 2000 UTC 23 December 1992 MM5 fields (Fig. 2(b)). Table 1 provides a synopsis of the control-simulation parameters for this case. In the early stages, initial convective bands form in locations 
(c) $3 \mathrm{~h}$

(a) $3 \mathrm{~h}$
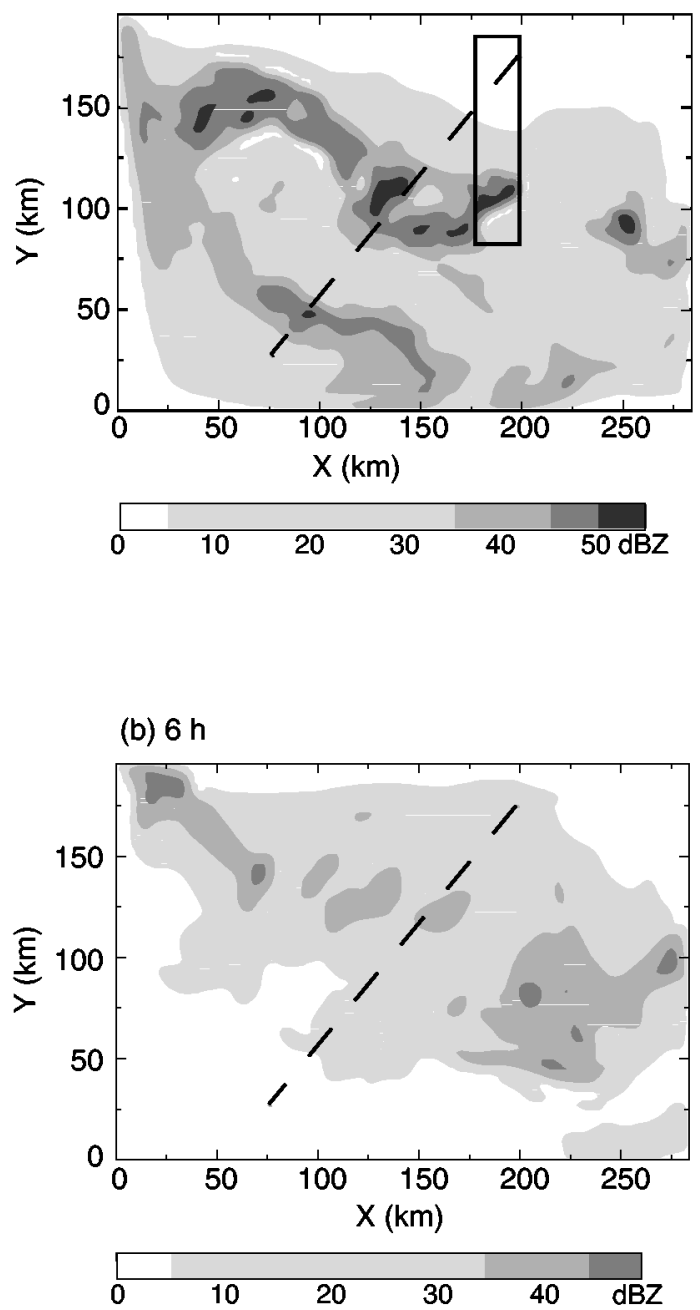
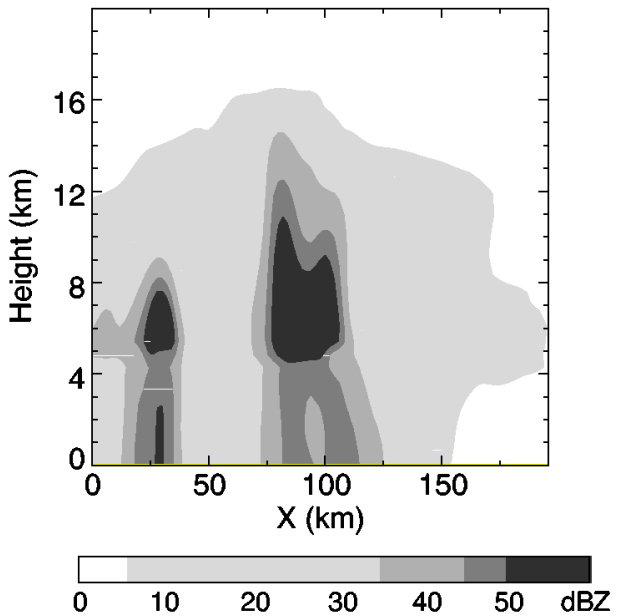

(d) $6 \mathrm{~h}$

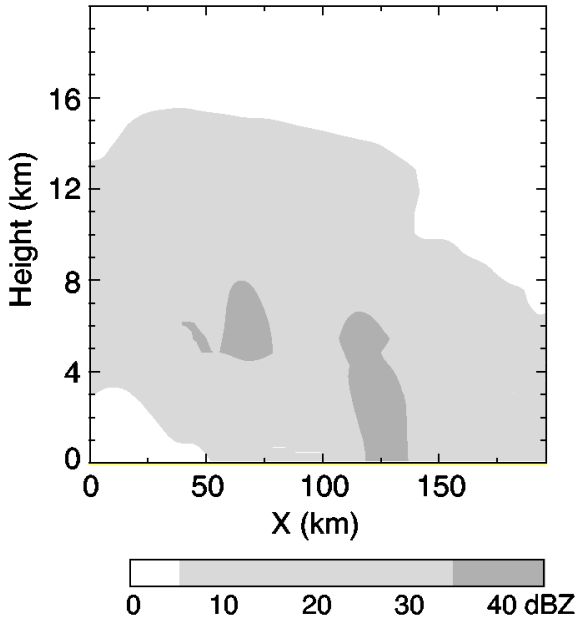

Figure 3. Model-derived radar reflectivity for the 23 December 1992 experiment: (a) and (b) 1 km horizontal cross-sections and (c) and (d) vertical cross-sections taken along the dashed lines in (a) and (b). The box in (a) indicates the horizontal span of the initial tracer distribution used in the trajectory calculations.

of horizontal confluence (Fig. 2). At three hours (Figs. 3(a) and (c)), an extensive region of precipitation has developed, structured in two main bands oriented from north-west to south-east. From the orientation of the cold pool (not shown), it can be inferred that the north-east side of the precipitation area is the leading edge that provides upward forcing for the storm-relative inflow. By 6 hours (Figs. 3(b) and (d)), the south-west band has decayed, and the cold pool has propagated toward the north-east as a density current. New convection forms along the propagating cold-pool boundary in an almost continuous cycle, and both convective and stratiform elements coexist. Calculating reflectivity from model output can be problematic and is quite sensitive to the assumptions made by the model microphysical parametrization. The 
(a)

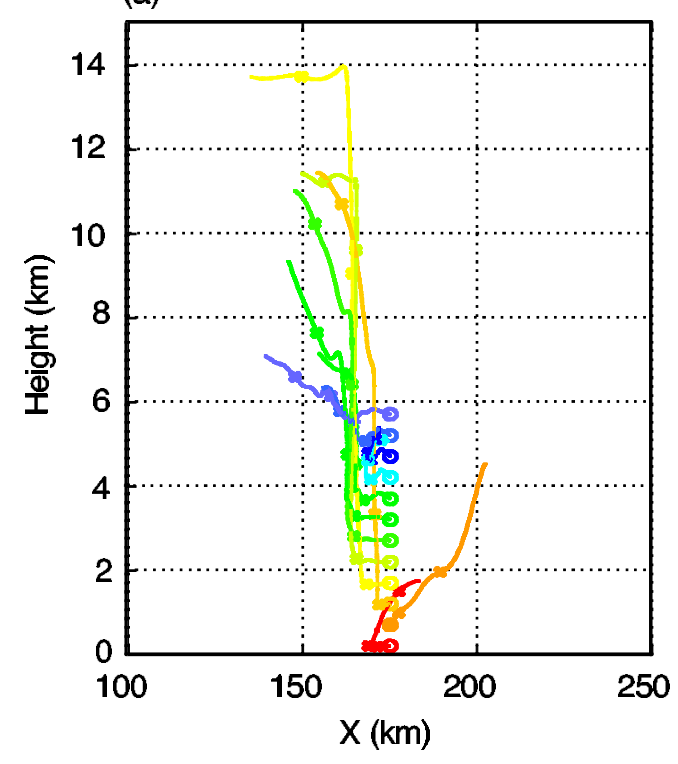

(b)

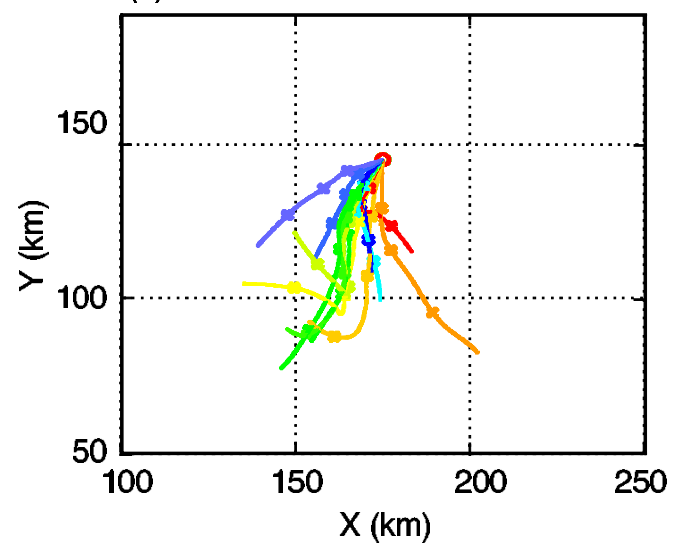

Figure 4. Two perspectives of 12 trajectories, each calculated over 3.5 hours of model time, for the 23 December 1992 experiment. Initial tracer locations are located $500 \mathrm{~m}$ apart in a vertical column. Initial locations are marked by o's, with hourly positions denoted by x's. (a) Projection of the trajectory paths onto the $x-z$ (west-east) vertical plane and (b) projection onto the $x-y$ (horizontal) plane.

calculation used here is rather crude, and while it produces reasonable spatial patterns, the magnitudes are significantly larger than those found in nature (Nesbitt et al. 2000).

Results from the ARPS simulation show a similar structure and evolution when compared with the 'parent' MM5 simulation. Both the MM5 and ARPS produce a twobanded structure, of which the south-western band decays with time. Another indication of how closely the solutions match is found near the boundaries. A smooth transition from the interior solution to the boundary zones is an indication that the models evolve in a similar manner. Furthermore, both ARPS and the parent MM5 simulation evolve in a manner similar to an actual MCS present in the 23 December 1992 satellite imagery shown in Fig. 1(b). It must be kept in mind that the ARPS simulations are incapable of capturing an entire MCS, much less the large cloud superclusters characteristic of the strong westerly region, but instead represent only a region or subset of an MCS. Some indications of banded structure are present in the satellite imagery. The simulated convection mimics the life cycles of the more intense areas, as inferred from cloud-top temperature. The individual convective bands move slowly toward the north-east in the ARPS and MM5 simulations, whereas they remain nearly stationary in the observations. The MM5 represents well the development of new convection toward the south-west of this large MCS, though of course the ARPS domain is far too small and its location too distant to capture it.

\section{(c) Trajectory analysis and layer inflow}

To investigate the nature of the inflow into the simulated convection, we used the method of Doty and Perkey (1993) to compute 600 earth-relative trajectories, calculated from ARPS output data beginning at $2 \mathrm{~h}$. The initial tracer locations are inside a volume $20 \mathrm{~km} \times 90 \mathrm{~km}$ in the horizontal and $5.7 \mathrm{~km}$ in the vertical, placed on the north-east 
(a)

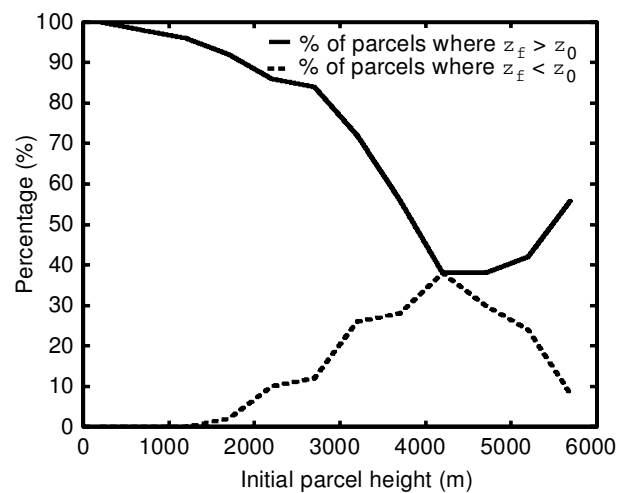

(c)
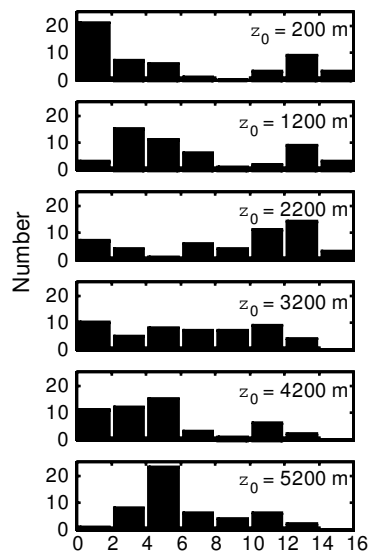

(b)
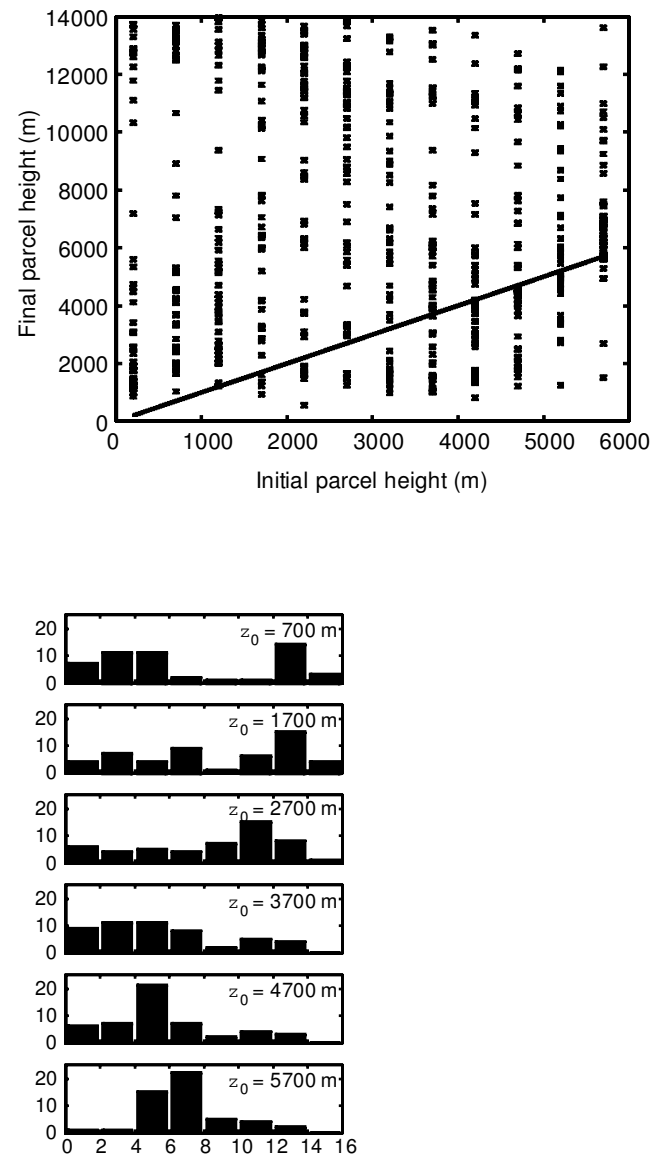

Final height $(\mathrm{km})$

Figure 5. Statistics calculated from all 600 trajectories for the 23 December 1992 experiment. (a) Percentage of trajectories whose final altitudes, $z_{\mathrm{f}}$, are $500 \mathrm{~m}$ higher (solid line) or $500 \mathrm{~m}$ lower (dashed line) than their initial altitudes, $z_{0}$. The sum need not add to $100 \%$. (b) Scatterplot of all 600 trajectories, plotted as tracer final altitude as a function of initial altitude. Plotted values lying along the line correspond to trajectories that experience little change in elevation over their paths. Points above the line indicate tracers that rise, and points under, tracers that descend. (c) Histograms, each indicating the final altitude distribution of the 50 trajectories corresponding to the indicated initial altitude.

side of the MCS (box in Fig. 3(a)) in an area judged to be an inflow region. Trajectories for a selected column of tracers are shown in Fig. 4. At low levels, the wind is mostly northerly at the initial time. The storm-relative motion which carries the tracers into the developing MCS is determined by a combination of the cold pool propagating toward the north-east and easterly winds being advected into the domain through the northern boundary. It is also likely that the system-generated pressure-perturbation pattern is acting to turn the wind with time such that it contains a more easterly component. After being transported toward the south-south-west for approximately an hour, the tracers in Fig. 4 enter a strong region of convective updraught, upon which nearly all of the trajectories ascend to varying degrees.

Figure 5 shows three different but related perspectives on the behaviour of the ensemble of trajectories. As expected and indicated by the sample column of trajectories, 
the layer mode of inflow is clearly present in this case. Near the surface and up to a level of $1200 \mathrm{~m}, 95 \%$ of the trajectories rise more than $500 \mathrm{~m}$. Even for trajectories with an initial altitude, $z_{0}$, of $4200 \mathrm{~m}$, nearly $40 \%$ ascend more than $500 \mathrm{~m}$. The character of the descending trajectories indicates that a significant number of the upper-level trajectories $\left(z_{0}=5700 \mathrm{~m}\right)$ experience very little change in altitude, with only $8 \%$ of trajectories descending more than $500 \mathrm{~m}$ from their initial altitude. The behaviour of the descending trajectories could be the result of weak evaporative cooling associated with near-saturation conditions over a deep layer, which could result in fewer descending trajectories. This sensitivity to mid-level environmental humidity is explored in section 5 .

The trajectory behaviour in the 23 December experiment is indicative of a strong layer-inflow signal, since a layer of air much deeper than the tropical boundary layer rises as it is ingested into the MCS. The next section discusses similar experiments made under the westerly onset regime and how the layer mode of inflow in the simulated convection is strongly modulated by the vertical thermodynamic structure of the inflow.

\section{CONVECTION IN THE WESTERly ONSET REGiON OF THE KELVIN-Rossby WAVE}

(a) Environmental conditions of the 14 December 1992 case

The 23 December case described in the previous section occurred during a westerly wind burst, a 2-3 week period of strong, deep westerlies and widespread occurrence of MCSs over the warm pool. The westerly wind burst was preceded by a westerly-onset period, 12-16 December, during which low-level westerlies and mid-level easterlies prevailed over the COARE area (Chen et al. 1996; Houze et al. 2000). This period marked the beginning of the frequent occurrence of large MCSs, after a long period of convective inactivity. The mid-to-upper tropospheric moisture increased during the onset period. The main differences between the onset period and late December were: (1) mid-level moisture was less than during the wind-burst period (Lin and Johnson 1996; Chen et al. 1996), (2) convective activity was intense but not as widespread as during the burst, and (3) the layer of westerlies was shallower than during the wind burst and overlain by easterlies in mid-levels.

On 14 December 1992 (Fig. 1(a)), westerly conditions were beginning to develop over the COARE region, and later in the day an MCS was observed in detail by the Doppler radar on board instrumented aircraft (Kingsmill and Houze 1999). The input data for the MM5 and ARPS models are not precise enough to simulate a specific system occurring on a given date. Nonetheless, by initializing the ARPS with the MM5 output for this day, we expected to simulate an MCS with properties reasonably similar to that observed by the aircraft. Accordingly, the first results we show are for the ARPS simulation initialized by MM5 output for 14 December 1992. The MM5 was initialized from the ECMWF global analysis fields, National Centers for Environmental Prediction global sea surface temperature analysis, and, where present, TOGA COARE soundings (Chen 1997). This method captures the large-scale flow field. Mesoscale variability, such as pre-existing precipitation or cold pools absent in the large-scale fields, 'spinup' in the MM5. The southern portion of the MM5 domain in Fig. 6(a) shows a region of convection that forms after the model spin-up has been accomplished. Convection begins three hours before the time shown, and a cold pool has rapidly propagated toward the east, triggering the new convection investigated in this study.

ARPS was employed in a manner similar to the 23 December experiment. The ARPS domain was $145 \times 101 \times 35$ points and was centred at $5.4^{\circ} \mathrm{S}$ and $161.9^{\circ} \mathrm{E}$. Initialization 
(a)

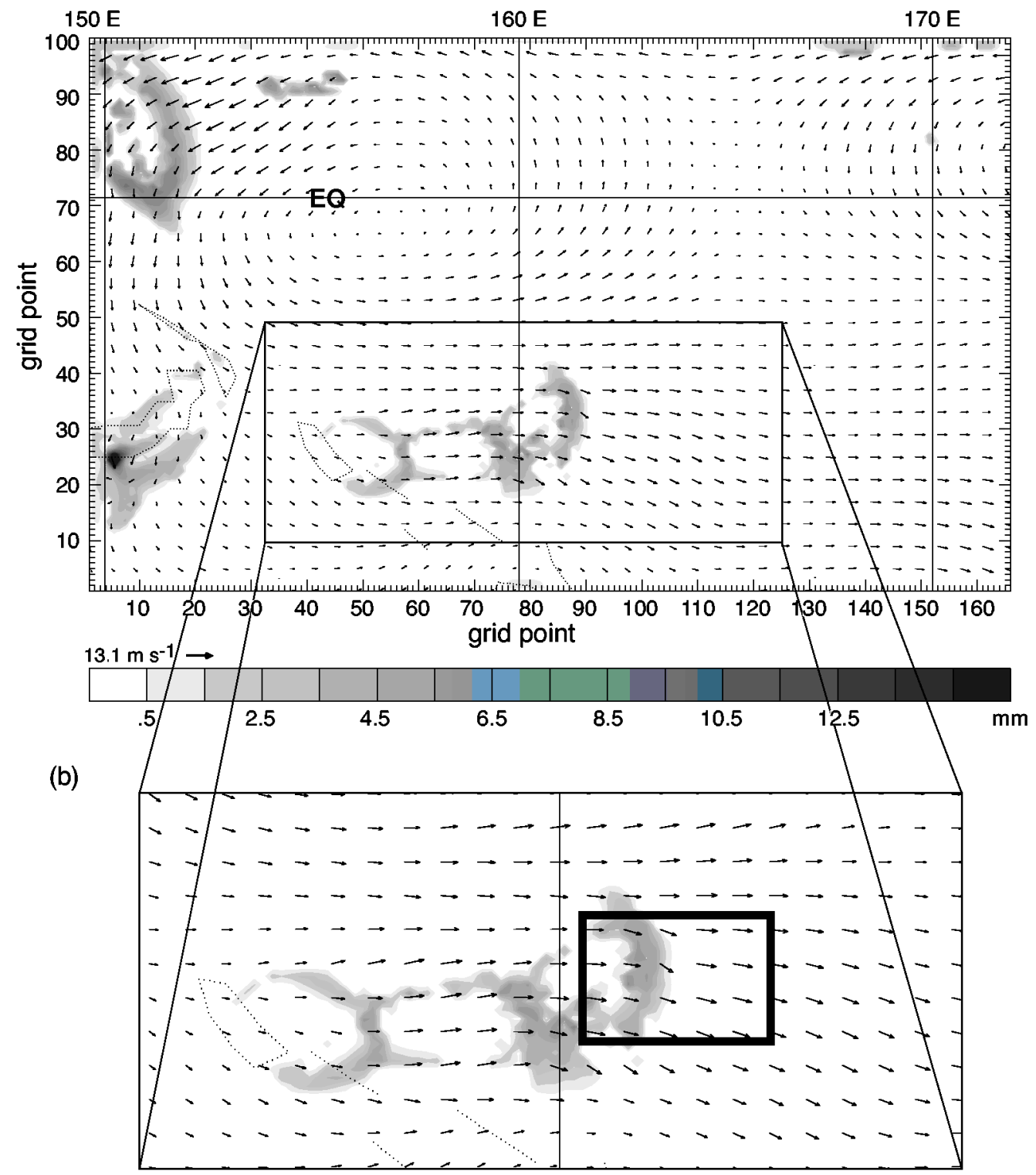

Figure 6. (a) 0800 UTC 14 December 1992 horizontal cross-section of $850 \mathrm{mb}$ wind and hourly accumulated surface rainfall from the $15 \mathrm{~km}$ grid of the MM5 simulation. (b) Magnification of the south-central portion of (a). The ARPS (see text) model domain is enclosed by the rectangle centred at $5.4^{\circ} \mathrm{S}, 161.9^{\circ} \mathrm{E}$.

data were a subset of the 0800 UTC 14 December 1992 MM5 fields (Fig. 6(b), chosen because of its location in a region of strong model-produced convection). The initialization time was at the early stages of the convection but late enough that precipitation and a significant cold pool had already formed. 


\section{(b) The 14 December simulation}

Figure 7 shows the evolution of the simulated convection via cross-sections of model reflectivity at hourly intervals. Early in the simulation, a broad band of precipitation oriented from north to south forms in response to a line of convergence oriented in the same manner. The line of convergence associated with the convection is stronger in the northern part of the domain, and the convection begins there earlier and is ultimately more intense. The system strengthens and becomes more organized between 1 and $2 \mathrm{~h}$, and by $3 \mathrm{~h}$ has already begun to weaken. The leading edge of the convection moves toward the east at a rate of $\sim 10 \mathrm{~m} \mathrm{~s}^{-1}$. After $3 \mathrm{~h}$, the system weakens and becomes more disorganized, with no new convection being triggered by the propagating cold pool.

The vertical cross-sections (Figs. 7(d) to (f)) show the evolving structure of the convection. At earlier times, the system is mostly convective in nature and is thus dominated by intense updraughts and downdraughts. As time advances, cloud ice and snow are advected toward the rear of the system (toward the west) where they grow by vapour deposition, aggregate and slowly precipitate. (Aggregation in the model occurs through the autoconversion of snow into the graupel field. Since the low fall speed of graupel in the model is similar to that of aggregates, the graupel field in the stratiform region may be thought of as being roughly representative of snow and ice aggregates. This view is consistent with McCumber et al. (1991).) When the precipitating ice hydrometeors melt, they produce a feature similar to a bright band at the melting level (Fig. 7(f)), even without accounting for the reflectivity enhancement associated with a liquid water layer on the snow particles falling through the melting zone. This frame also shows the leading edge of the cold pool, which has propagated $\sim 80 \mathrm{~km}$ ahead of the system. Evidently, the conditions at the gust front (Rotunno et al. 1988) do not favour additional convective development. What is left at this time is the decaying stratiform portion of the convection, which results from rearward advection of ice particles and their subsequent growth and sedimentation in the mid-to-upper levels in the remnants of older convective updraughts (Houze 1997).

Direct verification of the simulation is difficult and, although realistic initial and boundary conditions are used, it must be emphasized that the results do not represent any particular case-study but rather an idealized response to thermodynamic and flow profiles appropriate to a particular phase of the ISO. Nonetheless, the structure and evolution present in the simulation is consistent with TOGA COARE observations. Dual-Doppler radar observations from a portion of an MCS observed during TOGA COARE on 14 December, the day represented by the simulation, show the transition from a mostly convective to a more stratiform regime (Fig. 8). In its early stages, the system is characterized by vigorous, deep convective towers and a narrow region of intense rainfall at the surface (Figs. 8(a) and (c)). At this time, the system is associated with a region of horizontal convergence located near the strongest convective activity. The strong updraughts of the convective cells evidently lofted ice and snow particles high in the troposphere, where upper-level divergence spread them over a broad area, and a stratiform region subsequently developed in place of the earlier vigorous convection (Figs. 8(b) and (d)). In this stratiform phase, the snow particles settled, further increased in mass by vapour deposition and collection of cloud ice and finally melted and fell out as stratiform rain (Fig. 8(d)).

It should be kept in mind that the simulated system presented here is best thought of as being of a portion of an MCS, since the domain boundary is not able to circumscribe the entire MCS. This may be one reason that the simulated MCS has a markedly shorter life span than the convection observed on 14 December. The simulated convection lasts 

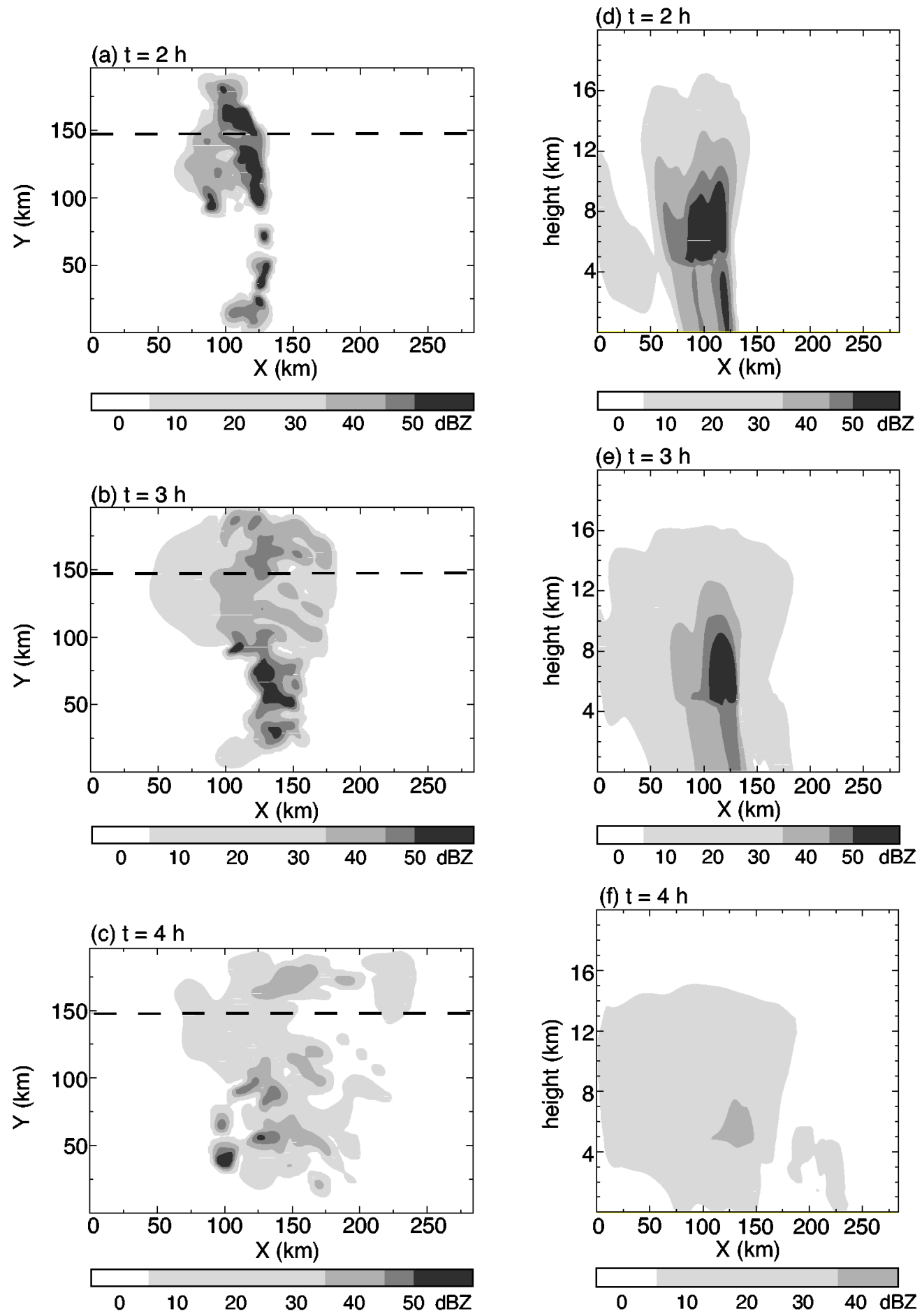

Figure 7. Model-derived radar reflectivity for the 14 December 1992 control experiment: (a)-(c) 1 km horizontal cross-sections taken at hourly intervals and (d)-(f) vertical cross-sections (indicated by dashed lines in (a)-(c)) taken through the northern part of the convective system. 


\section{(a) 1827 UTC}

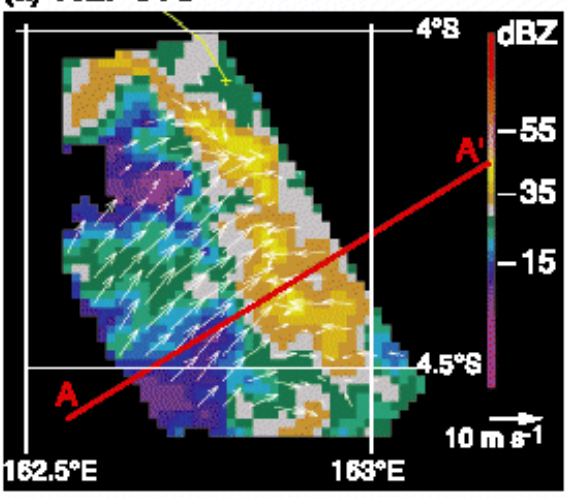

\section{(b) 1827 UTC}

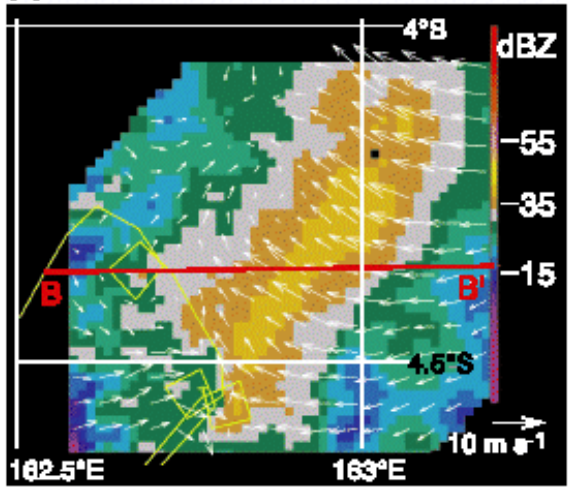

\section{(c) 1627 UTC}

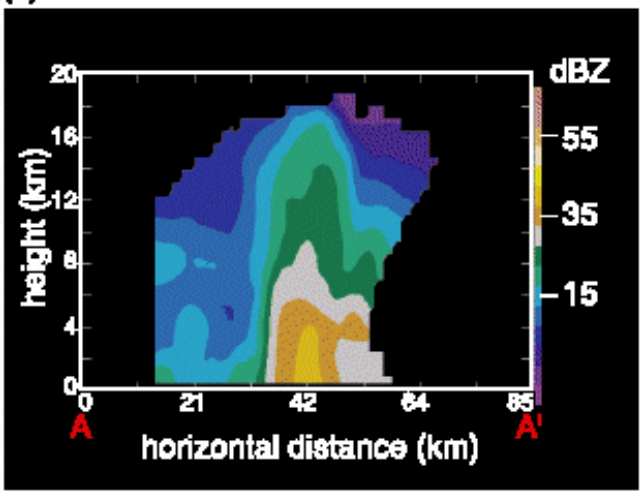

\section{(d) 1827 UTC}

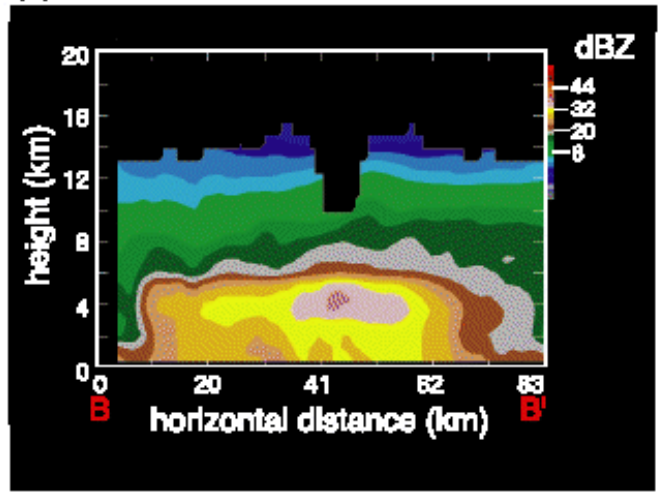

Figure 8. Airborne dual-Doppler radar data obtained by a NOAA P3 aircraft during the TOGA COARE field project on 14 December 1992 (flight track in yellow). Filled contours indicate radar reflectivity and superimposed vectors indicate the measured horizontal wind velocities. Panels (a) and (b) are $4.4 \mathrm{~km}$ mean-sea-level horizontal cross-sections and panels (c) and (d) are vertical cross-sections taken through the red lines in (a) and (b) respectively.

for $<4 \mathrm{~h}$, while a typical MCS lifetime determined by cloud-top infrared temperature criteria is $10 \mathrm{~h}$ (Houze 1993). However, the simulation does capture reasonably well the temporal transition from convective to stratiform, visible in the observations (cf. Figs. 7 and 8) on that day.

\section{(c) Trajectory analysis: parcel mode}

As in the 23 December case, 600 earth-relative trajectories were computed from the ARPS output. For the model time interval 1-5.5 h, we computed trajectories every six seconds from model data that had been output every two minutes. The initial trajectory locations were inside a volume $20 \mathrm{~km} \times 108 \mathrm{~km}$ in the horizontal dimension and $5.7 \mathrm{~km}$ in the vertical (12 vertical levels of 50 points each). This region was the source of the storm's inflow air (Fig. 9). The lower-level wind is mostly northerly at the beginning of the trajectory calculation. However, in the storm-relative sense the flow is easterly; the tracers enter the convective system on its east side. 


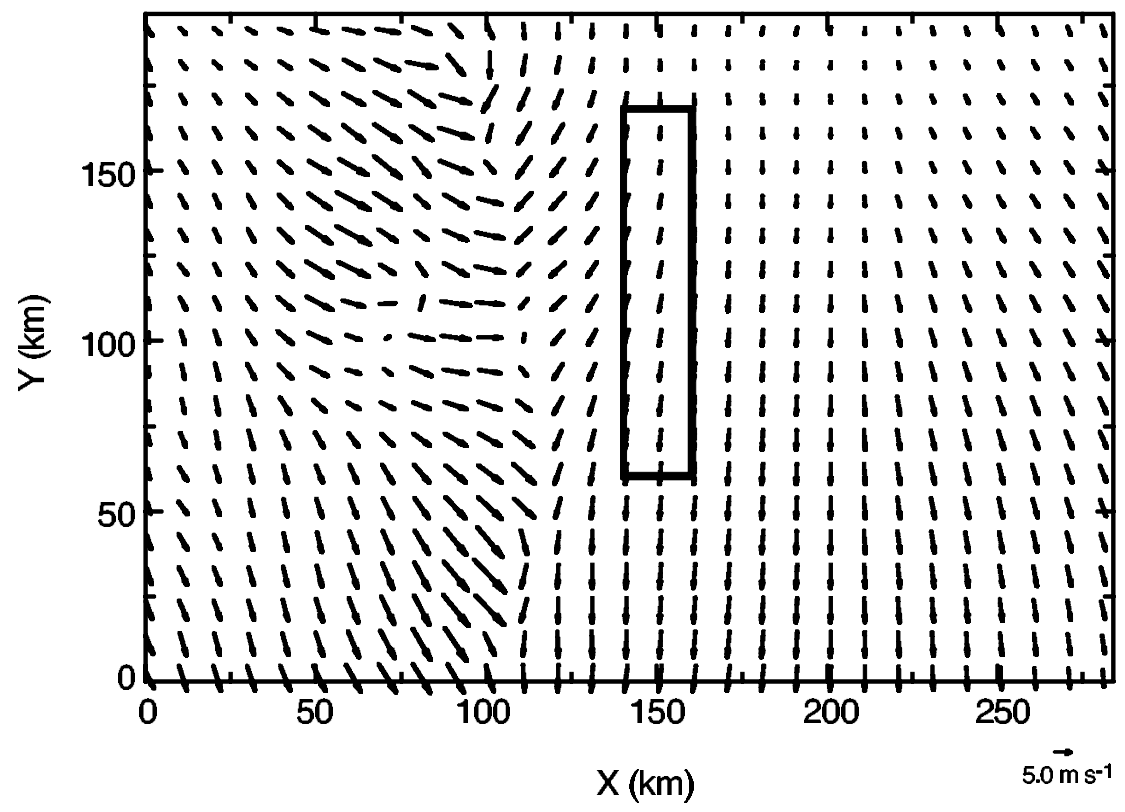

Figure 9. The horizontal span of the initial tracer distribution, indicated by the box and overlaid on the $1 \mathrm{~h}$ surface wind field.
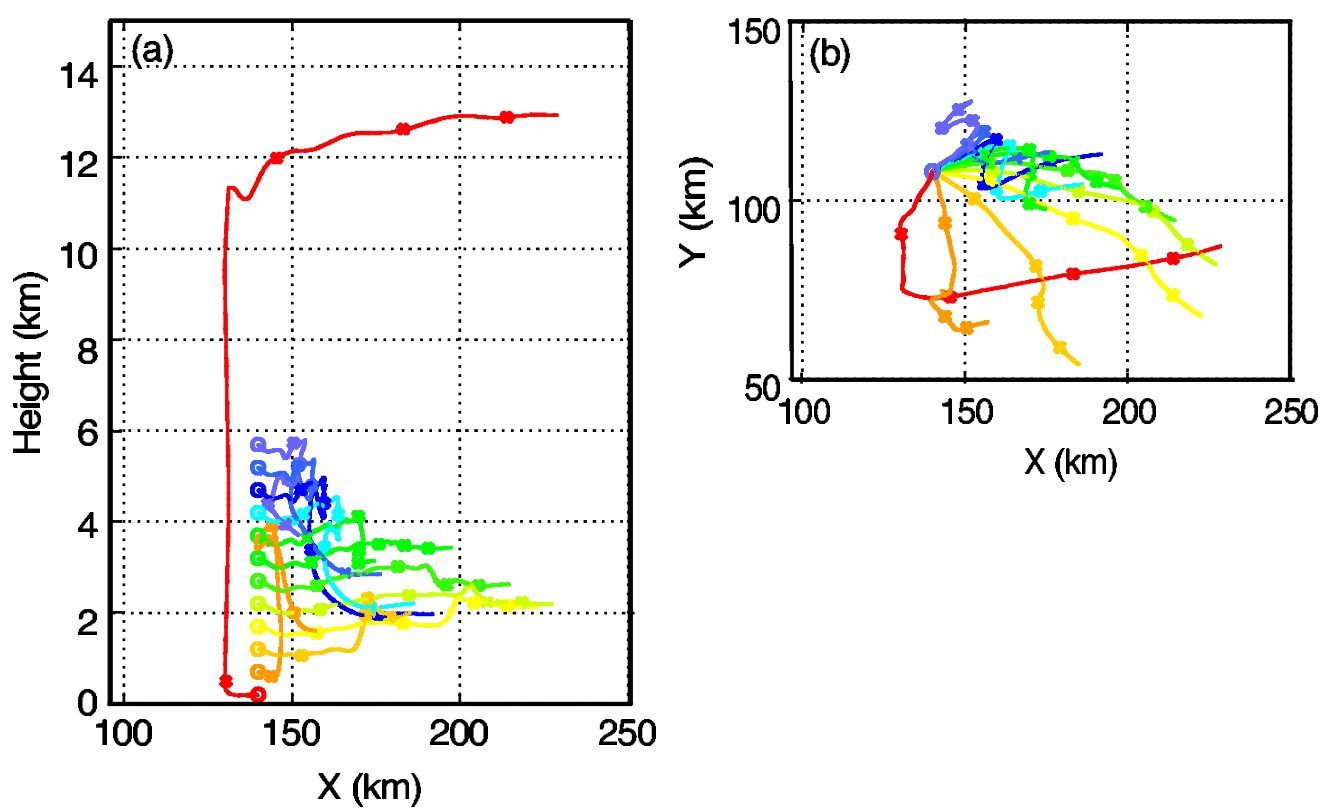

Figure 10. Two perspectives of 12 trajectories, each calculated over 4.5 hours of model time for the 14 December 1992 control experiment. See Fig. 4 for explanation. 
(a)

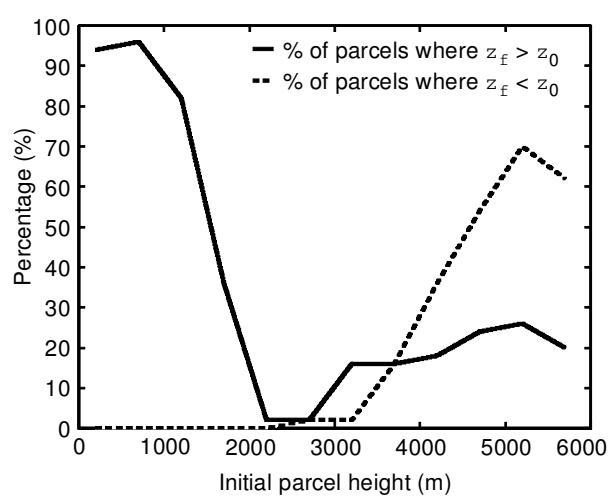

(b)

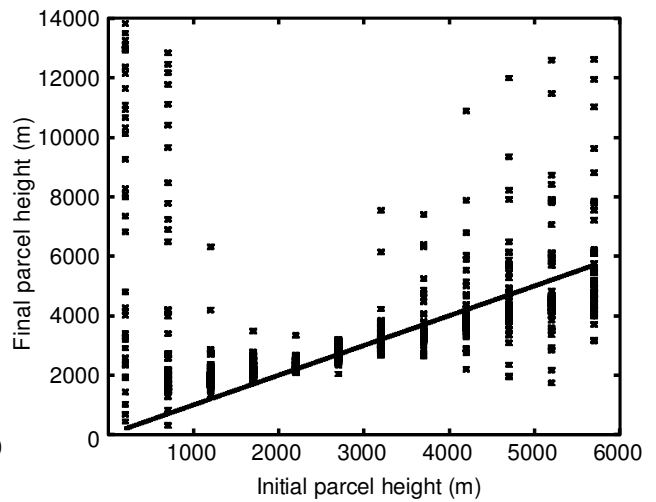

(c)
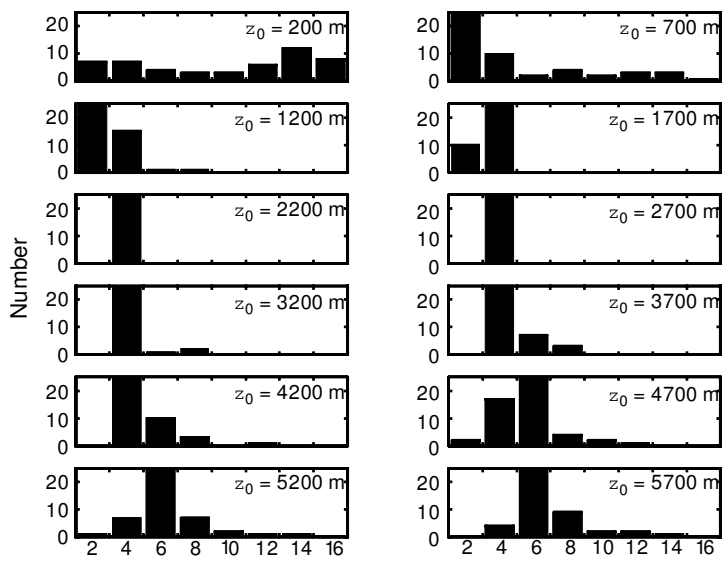

Final height $(\mathrm{km})$

Figure 11. As in Fig. 5, but for the 14 December 1992 control experiment.

Figure 10 shows a small sample of trajectories whose initial positions are aligned in a vertical column. Only tracers initially near the surface are prone to rise a significant distance. Tracers initially higher in the column sink or remain at the same level. This is a characteristic of the crossover-zone conceptual model, even though the quasi-twodimensional portrayal of the crossover zone in this simulation is sometimes difficult to identify. Since the vertical wind profiles exhibit significant directional and speed shear with height, the entire concept of layer can be figuratively twisted.

Figure 11 is similar to Fig. 5. It shows three different but related perspectives on the behaviour of the ensemble of trajectories. Figure 11(a) shows the likelihood of a parcel to ascend (solid line) or descend (dashed line) $500 \mathrm{~m}$ from its initial height. Trajectories initially near the surface are very likely to rise, but the percentage that rise drops off significantly with height until, at $2200 \mathrm{~m}$, fewer than $3 \%$ rise more than $500 \mathrm{~m}$ above their initial height. For trajectories initially at the lowest vertical level (200 m height), $95 \%$ of the final locations are $500 \mathrm{~m}$ above the initial locations, and many of the final locations are at extremely high altitude. A significant number $(19 / 50=38 \%)$ ascend to approximately $13 \mathrm{~km}$. 
Above $3000 \mathrm{~m}$ the number of trajectories that descend more than $500 \mathrm{~m}$ from their original altitude increases significantly with height and peaks at $70 \%$ above $5200 \mathrm{~m}$, though most of these only descend a kilometre or two. Inspection of the scatterplot (Fig. 11(b)) and the histograms (Fig. 11(c)) shows that few of these trajectories ascend through as deep a layer as do those with initial heights near the surface.

These statistics are largely consistent with the crossover zone of the conceptual model. The boundary-layer air, characterized by large $\theta_{\mathrm{e}}$, is most apt to rise, while the drier air lying just above is mostly entrained into the updraughts and downdraughts, becoming negatively buoyant and sinking. After being entrained into the convective region, the middle part of the layer achieves neutral buoyancy, and hence the tracers neither rise nor sink significantly. A few tracers initiating at levels above $3000 \mathrm{~m}$ rise. Zipser (1977) mentions the possibility that a small percentage of mid-level ambient air might mix with a relatively large percentage of updraught air, causing some parcels of ambient air to rise. Although the tracers originating in the upper part of the layer sink, their descent appears to be less than what might be expected from the conceptual model, where the relatively dry, upper part of the layer enters the convective zone and helps initiate and enhance mesoscale unsaturated downdraughts. This process seems to be occurring only in a limited fashion in the model, though it should be noted that the low- $\theta_{\mathrm{e}}$ air at model mid-levels is several degrees larger than that in the conceptual model $(335.5 \mathrm{~K}$ in the simulation versus $332 \mathrm{~K}$ in the schematic diagram of the conceptual model from Zipser (1977)). Thus, perhaps less strengthening of the downdraughts and less downward movement of the tracers might be expected given the model environmental conditions.

We tested the trajectory statistics by changing the initial positions and times of the trajectories. Moving the initial tracer locations small amounts in the horizontal ( $1 \mathrm{~km}$ to the east and $1 \mathrm{~km}$ to the north of the control-case locations) results in some large changes in final locations, both horizontally and vertically; however, the ensemble properties of the trajectories remain virtually unchanged. The trajectories are somewhat sensitive to the initial calculation time. When releasing the trajectories in the system inflow, some care is needed in choosing the initial time. Beginning too early means the tracers reach the convective region before it has had a chance to fully form and spin-up; beginning too late means the tracers never reach the convection but rather head to the south and subsequently to the east. The trajectory statistics are quite similar for initial calculation times between 1 and $1.5 \mathrm{~h}$.

\section{(d) The nature of observed inflow on 14-15 December 1992}

Although the trajectory calculations indicate that the crossover conceptual model seems appropriate for the simulated convection of the control run, radar observations on this day contain evidence of a deep layer of inflow, the whole of which appears to rise upon entering the convective system (Fig. 12). The system observed by aircraft between 1630 and 1830 UTC has sloping layer inflow from the west, while the relative inflow produced by the model is shown by the trajectories to be largely from the east. This behaviour of the model is not really at odds with the observations. Chen et al. (1996) applied a tracking algorithm to infrared satellite imagery to show the long-term movement of large tropical cloud clusters. Figure 11(d) of Chen et al. (1996) shows a bifurcating propagation in which the 14 December cloud system splits into eastward and westward propagating systems. In addition, a significant eastward propagating system occurred on 15 December. These opposing movements in the satellite observations suggest that the same system had portions of convection with different inflow directions. The direction of propagation is determined largely by the ambient shear (Rotunno et al. 

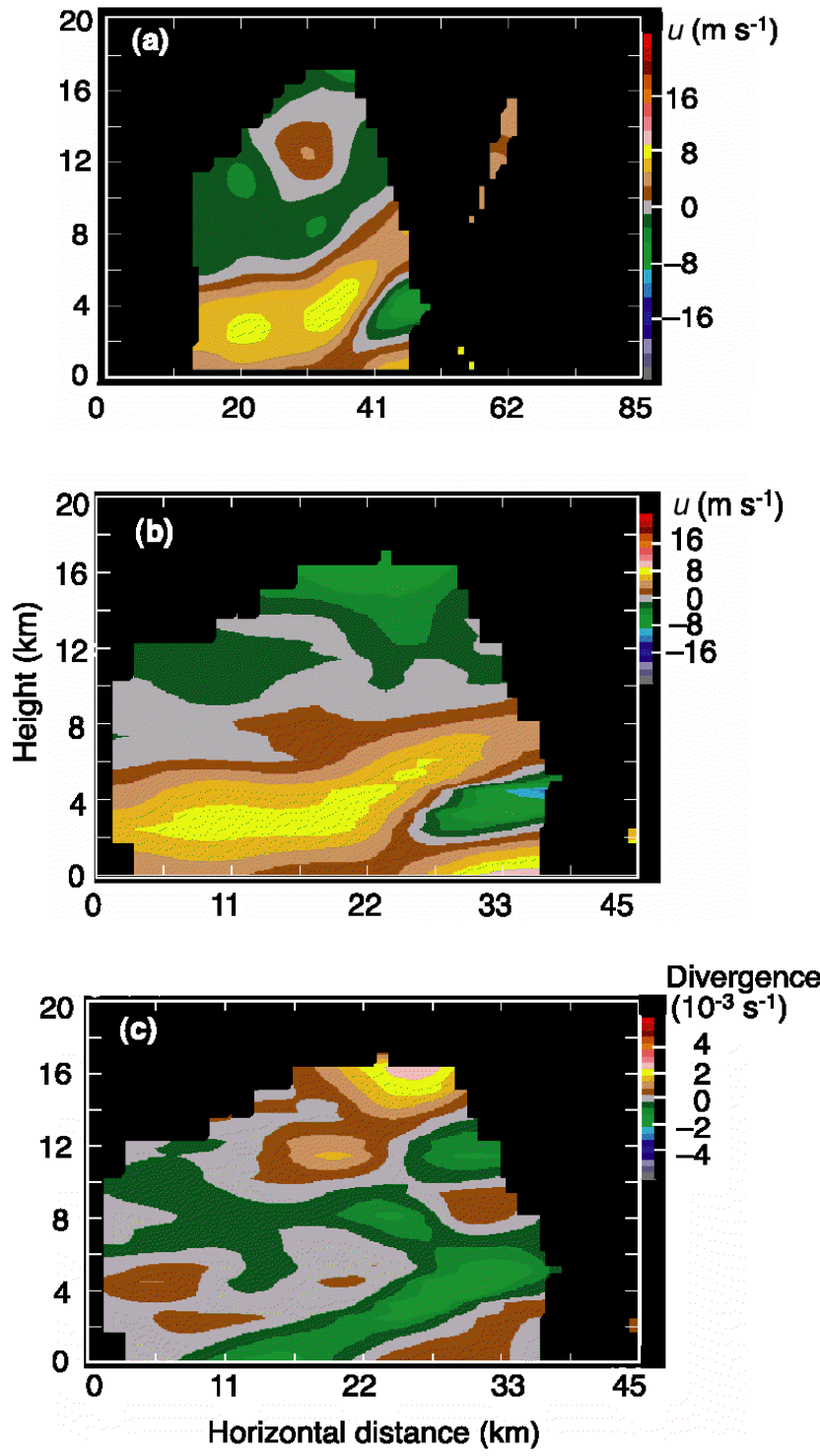

Figure 12. Airborne dual-Doppler analysis of part of a convective system observed on 14 December 1992. (a) Vertical cross-section of $u$ velocity at 1627 UTC taken along line A-A' in Fig. 8. Yellows and browns indicate positive $u$; greens and blues correspond to negative $u$. Vertical cross-sections of (b) $u$ velocity and (c) horizontal divergence at 1635 UTC taken along a similar, shorter line while the system is still quite convective in nature.

Regions of green indicate convergence, yellows and browns indicate divergence. 

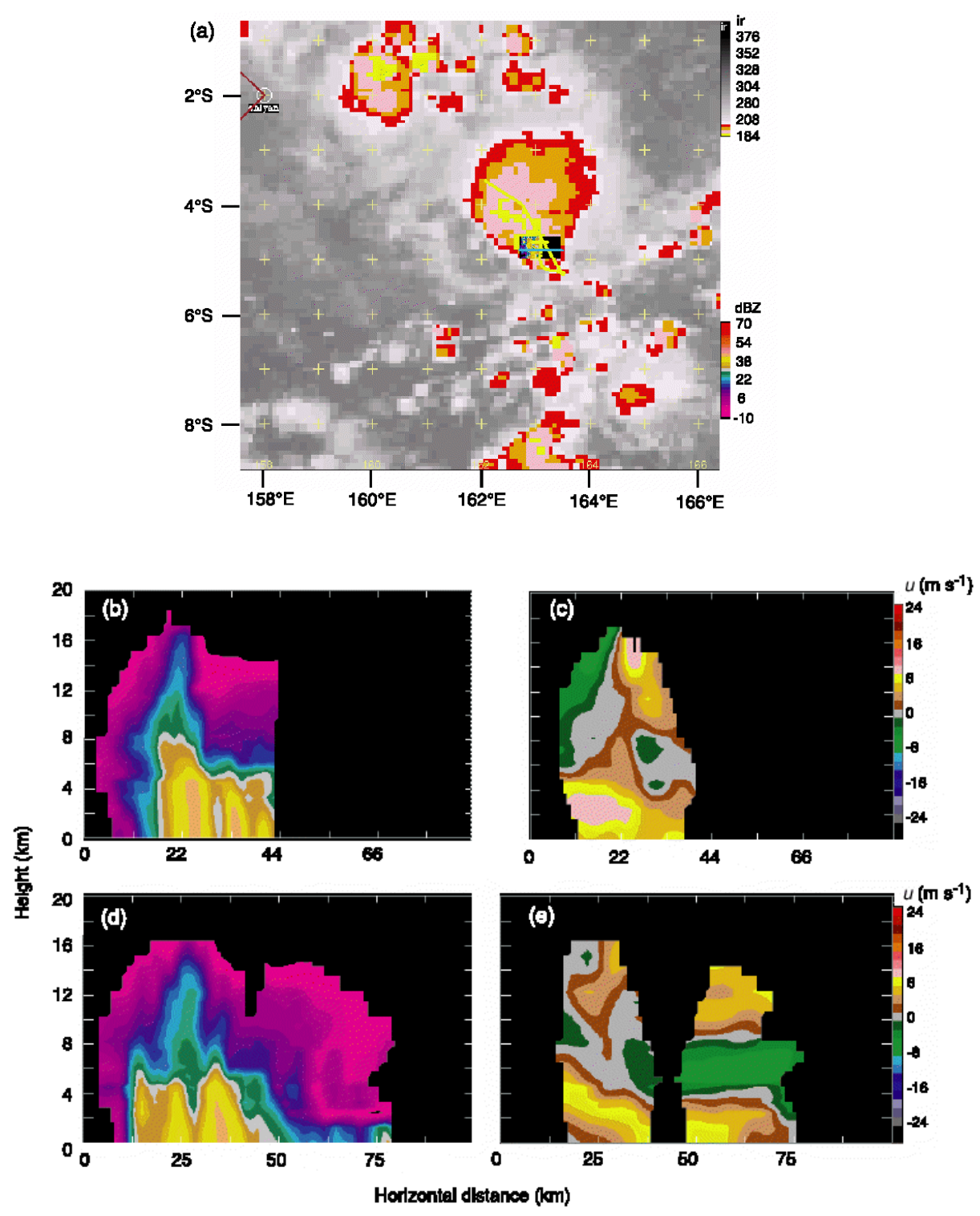

Figure 13. Airborne radar reflectivity and dual-Doppler analysis of the southern part of a large mesoscale convective system for 1700 UTC on 14 December 1992. (a) Reflectivity overlaid on infrared cloud temperature (K), and vertical cross-sections of radar reflectivity and $u$ velocity taken through predominantly west-east orientation at (b) and (c) 1700 UTC and (d) and (e) 1715 UTC respectively. 


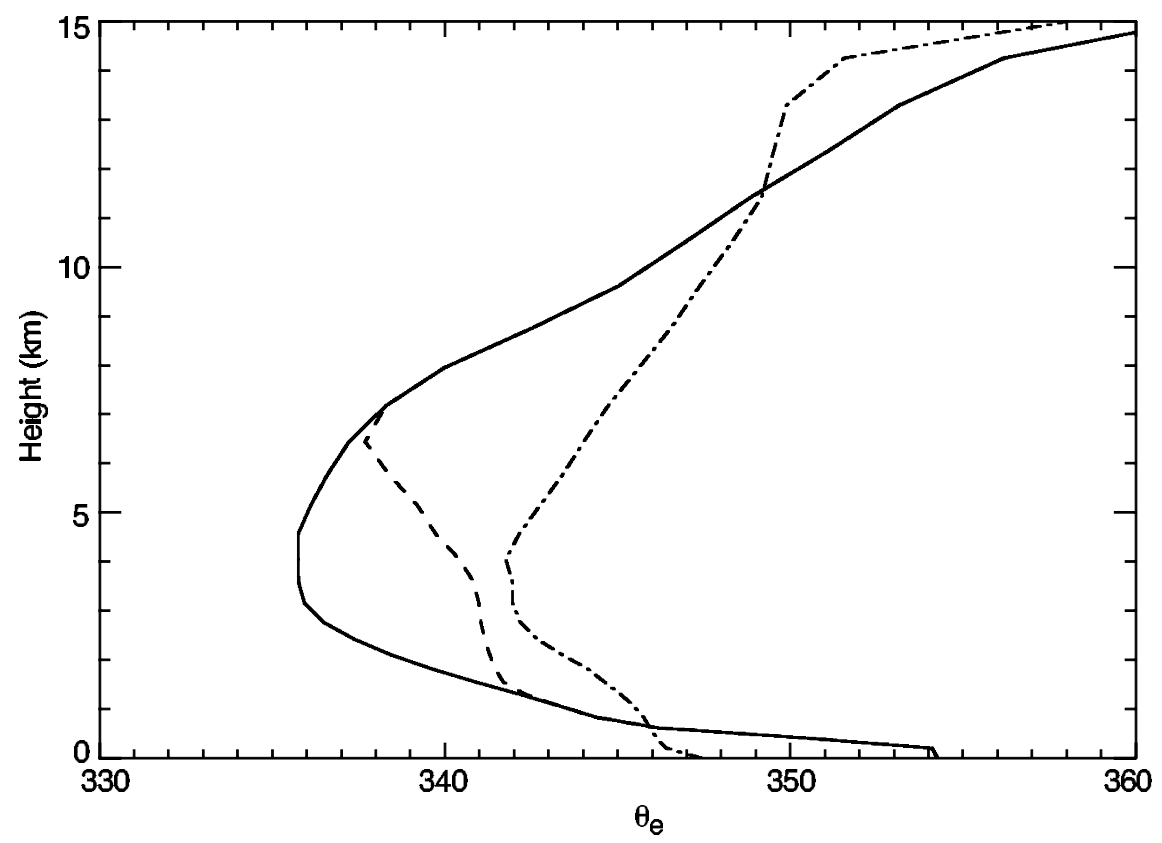

Figure 14. Representative equivalent potential temperature, $\theta_{\mathrm{e}}(\mathrm{K})$, profiles in the inflow region of the simulated mesoscale convective systems for the 14 December control (solid line), the 14 December enhanced-moisture (dashed line), and 23 December (dash-dot line) experiments at the initial model times.

1988), though observations indicate it can also be affected by vertical transports of momentum (Houze et al. 2000). Houze et al. (2000) suggest that in the westerly onset region, the large-scale shear favours mid-level easterly inflow in the early stages of convection. They suggest that a mature MCS with a significant region of stratiform descent is able to transport mid-level easterly momentum downward, favouring new convection on the west side of the MCS, which is characterized by low-level westerly inflow (see their Fig. 25). In their analysis of aircraft dual-Doppler radar data collected on 14 December, Kingsmill and Houze (1999) found multiple storm-relative inflow directions in three different regions of convection on 14 December (see their Table 4). Figure 13 shows a region where the inflow was easterly. This piece of convection, sampled by the aircraft from 1700 to 1715 UTC, was south of the region shown in Fig. 14 and was likely at an earlier stage in its life cycle. The easterly inflow that appears in the model inflow seems more consistent with this portion of the convection.

\section{PROCESSES DETERMINING PARCEL OR LAYER INFLOW}

As noted in the previous section, the mid-levels were drier in the initial conditions used to represent 14 December than in the 23 December case. This section describes a numerical experiment designed to isolate the effect on the inflow of the mid-level environmental moisture. We perform a sensitivity test on the 14 December case by increasing the mid-level moisture in the initial conditions of the model run.

\section{(a) Enhanced-moisture experiment}

The data in Figs. 12 and 13 show deep layers of inflow, in contradiction to the model results, which suggest a parcel-lifting scenario - the only air reaching high levels 
being parcels originating from near the ocean surface. We suggest that this parcel lifting occurs in the model because of the dry mid-levels in the model input data. Figure 14 shows thermodynamic profiles taken in the inflow region of the simulated MCSs. Midlevels of the 23 December experiment, in which the layer inflow mode was present, are significantly moister by comparison. The goal of our sensitivity experiment was to test whether the parcel lifting in the 14 December simulation would be replaced by a layertype inflow if the mid-levels were moistened. The experiment makes no assumptions about the mechanism that causes the moistening, although some possible mechanisms will be discussed below.

For the sensitivity experiment, the relative humidity was set to $95 \%$ for all points in the domain between 1700 and $6000 \mathrm{~m}$ altitude. The new mean inflow profile is plotted on Fig. 14. Rationale for this choice is that Kingsmill and Houze (1999) found that the depth and breadth of the convection, and hence its degree of organization on the mesoscale, to have been correlated with the humidity of air entrained into the system at low to middle levels. The moistening is therefore reasonable, even if the exact mechanism or mechanisms are not understood.

The simulated radar reflectivities in Fig. 15 compared with those in Fig. 7 provide an overview of the sensitivity experiment. Adding mid-level moisture results in convection that is horizontally more extensive than that in the control simulation. It has a more extensive stratiform region, and the convection cells are stronger. The temporal development of the two runs is quite different. In the enhanced-moisture experiment, the convective region is maintained longer, and the stratiform region develops earlier. New convective cells form behind (to the west of) the leading line but are unable to maintain their intensity, transitioning rapidly into small but numerous regions of stratiform precipitation that subsequently aggregate in time (Houze 1997). In contrast to the control case, new convective elements are triggered at the edge of the cold pool. According to the reasoning of Rotunno et al. (1988), the slightly deeper (though weaker) front edge of the cold pool in the enhanced-moisture experiment produces a more ideal balance between vorticity generated by the cold pool and that present in the ambient flow. For these reasons the convective system in the sensitivity experiment exhibits a better-defined spatial pattern of convective and stratiform structure, where both elements are present together for a longer period of time, and the system more slowly evolves to its dissipative stage. An additional reason for the slower evolution may be that the increase in mid-level humidity modulates the intensity of the cold pool. Early in the life of the system, when convective cells dominate, the cold-pool temperature perturbation for the control case is $-4 \mathrm{~K}$, while for the sensitivity case it is only $-2 \mathrm{~K}$. The enhanced humidity leaves less potential for evaporation of rain and melted ice particles. The cooling in the sensitivity experiment results more from melting of ice particles than from evaporative processes. In the control case, evaporation is dominant for the early-to-mid stages of the system, but eventually the evaporation from falling hydrometeors nearly saturates the middle levels.

In addition to greater spatial extent, the convection in the sensitivity experiment is more intense, having stronger updraughts and downdraughts than the control results. A moister environment producing more intense convection is in agreement with Lucas et al. (2000), although both the control and sensitivity results seem to be more intense than in their corresponding experiments. The reason for this difference is not immediately clear, though the difference in initialization methods is the most logical possibility, since the microphysical and subgrid schemes are quite similar. Lucas et al. (2000) conclude that the stronger updraughts in the enhanced-moisture case result from decreased dilution via entrainment of mid-level environmental air. This seems to be the case for 
(c) $t=2 h$
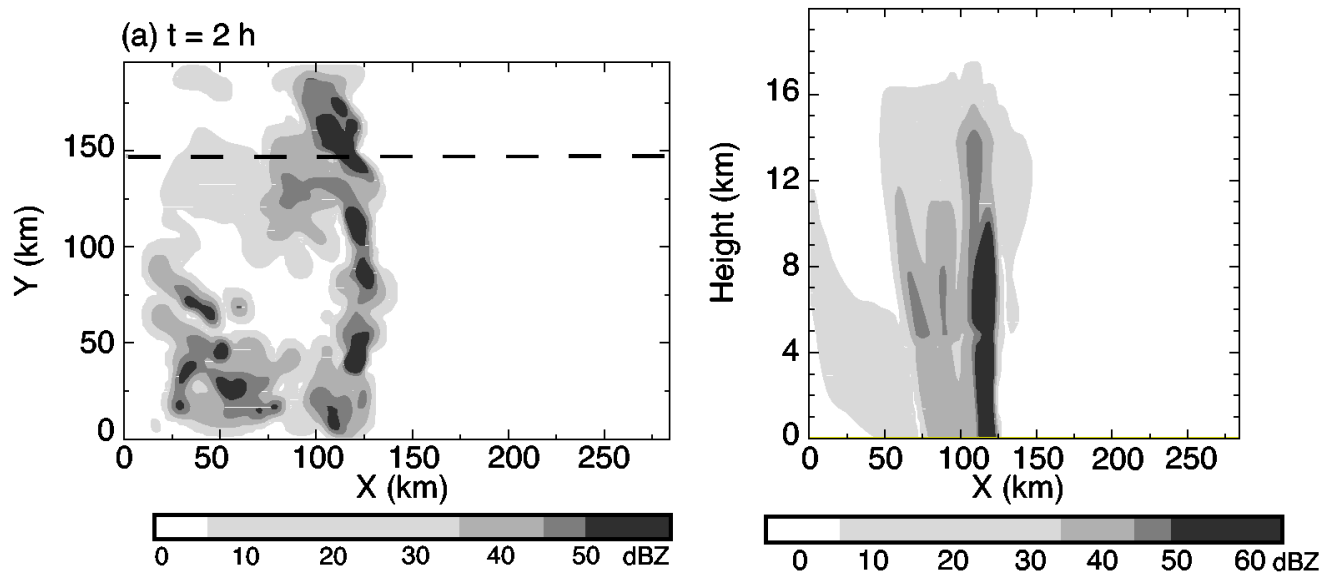

(d) $\mathrm{t}=4 \mathrm{~h}$

(b) $t=4 h$
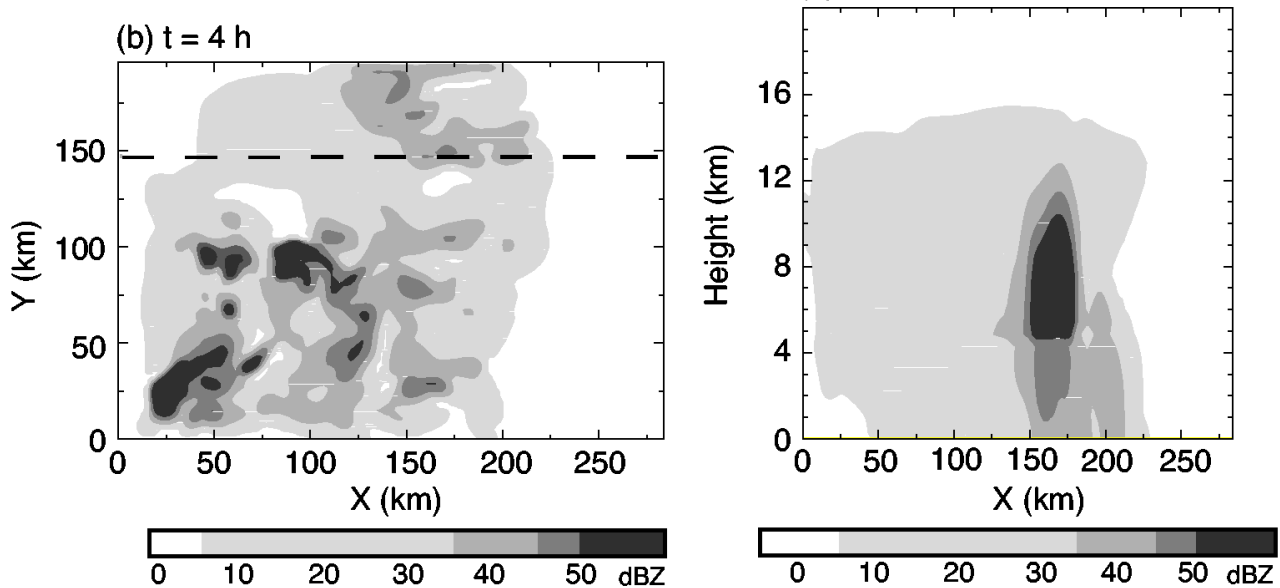

Figure 15. Model-derived radar reflectivity for the 14 December 1992 enhanced mid-level moisture experiment: (a) and (b) $1 \mathrm{~km}$ horizontal cross-sections taken at 2 and $4 \mathrm{~h}$ and (c) and (d) vertical cross-sections (indicated by the dashed lines in (a) and (b)) taken through the northern part of the convective system.

the enhanced-moisture experiment in this study, too, although the results do not (for the reasons stated above, regarding saturation deficit) appear to extend to the cold-pool magnitude.

\section{(b) Trajectory analysis of the enhanced mid-level moisture experiment}

Trajectories were calculated for the sensitivity experiment using the same initial block of points. The number and initial tracer locations are the same as for the control case, and trajectories computed from a single column of initial points are shown in Fig. 16. Whereas for the control case (Fig. 10) only tracers in the lowest few hundred metres ascend, tracers in this case show more of a tendency to ascend a significant distance. Only a few of the tracers represent air being entrained into the downdraught, becoming negatively buoyant and sinking. As in the control case, the final tracer horizontal locations can be significant distances from each other. 
(a)

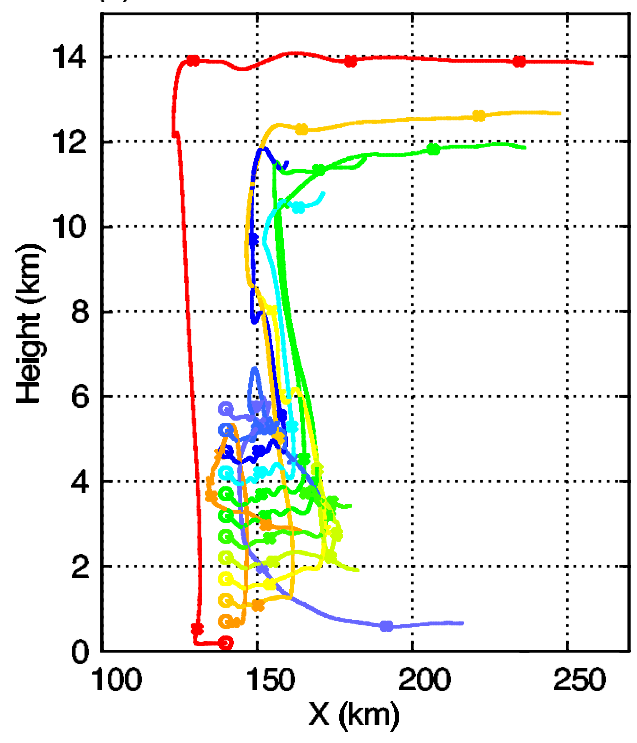

(b)

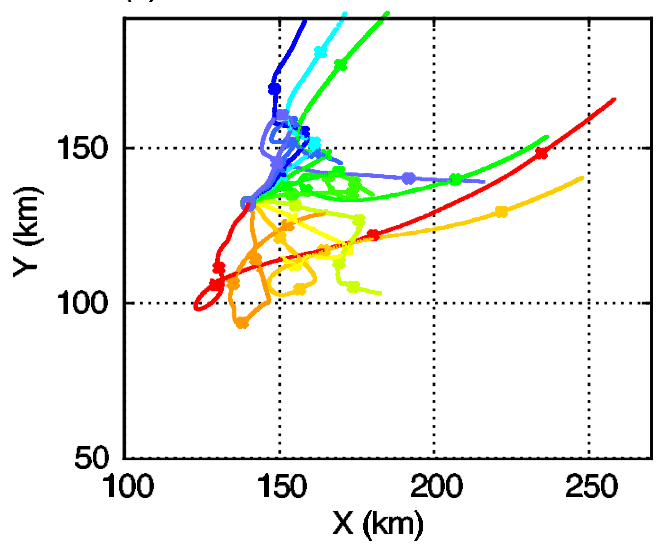

Figure 16. As in Fig. 10, but for the 14 December 1992 enhanced mid-level moisture experiment.

Figure 17 shows the statistical behaviour of the ensemble of trajectories for the sensitivity run. As for the control case (Fig. 11), the tracers initially near the surface are very likely to rise. The depth for which $95 \%$ rise more than $500 \mathrm{~m}$ above their initial level is $1700 \mathrm{~m}$. Above $1700 \mathrm{~m}$, the percentage that rise decrease but less so than for the control case. In the control run, only $3 \%$ of the tracers with initial altitudes of $2200 \mathrm{~m}$ ascend more than $500 \mathrm{~m}$, while nearly $75 \%$ do so in the environment with enhanced midlevel moisture. For points beginning at $4700 \mathrm{~m}$, nearly $40 \%$ ascend, and the scatterplot (Fig. 17(b)) and distribution (Fig. 17(c); $z_{0}=4700 \mathrm{~m}$ ) show that, unlike for the control experiment (Fig. 11(c)), a significant number of these trajectories extend a significant distance upwards.

The percentage of tracers at upper levels of the inflow layer which descend more than $500 \mathrm{~m}$ is similar for both experiments, and the scatterplots and histograms reveal that the descent is in general greater for the case with the enhanced moisture. This initially seems wrong from a parcel-mixing perspective, because dry mid-level air entering a system and mixing with a saturated downdraught would tend to cool the downdraught via evaporation. However, results from numerical experiments investigating microbursts (Srivastava 1985) show that a moist middle level in the environment humidity profile can actually enhance the strength of some downdraughts (and hence, the tendency for the tracers to descend farther), since the contribution of the moisture perturbation in the buoyancy term becomes more negative as the base state mixing ratio increases. The peculiar behaviour of the descending tracers in the control experiment may arise from the lack of robust, mesoscale unsaturated downdraughts. The time-scale of the simulated convection is shorter than in nature, and it is unlikely that these downdraughts are able to fully form over the relatively short duration of the simulation. 
(a)

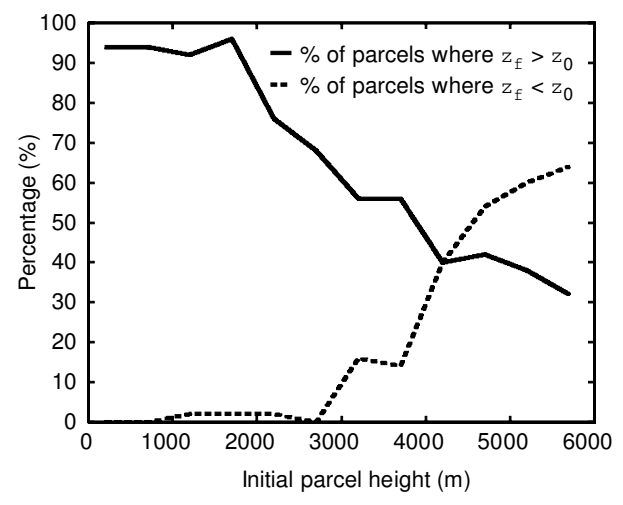

(c)

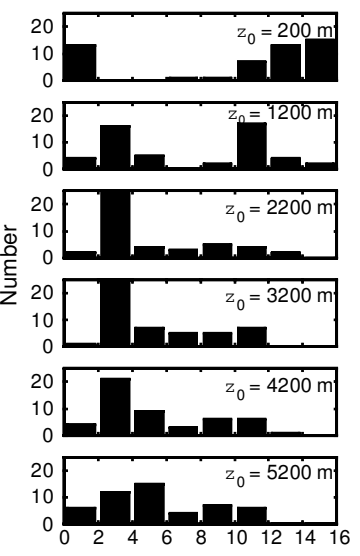

(b)
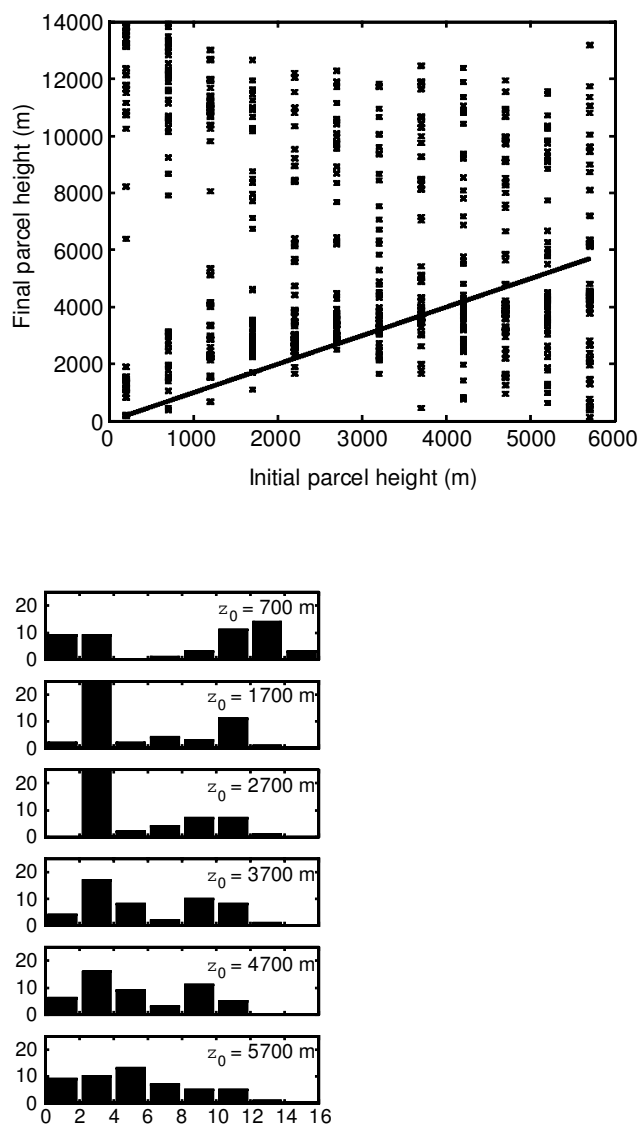

Final height $(\mathrm{km})$

Figure 17. As in Fig. 5, but for the 14 December 1992 enhanced mid-level moisture experiment.

\section{(c) Thermodynamic differences between the model experiments}

The control-experiment profile in Fig. 14 is similar to the 'fair weather' category described by Lucas and Zipser (2000), with a dry mid-level $\theta_{\mathrm{e}}$ of $\sim 335 \mathrm{~K}$ and characterized by isolated showers and small MCSs. The profile from the sensitivity experiment is more similar to Lucas and Zipser's (2000) active category, which has a mid-level $\theta_{\mathrm{e}}$ of $\sim 340 \mathrm{~K}$ and is accompanied in the model by extensive deep convection and layer inflow, as demonstrated by trajectory analysis. The profile from the 23 December experiment is even moister and also exhibits layer inflow.

Horizontal cross-sections of $\theta_{\mathrm{e}}$ along the direction of the storm-relative inflow show significant thermodynamic differences between the control and the enhanced mid-level moisture experiments. The cross-section in Fig. 18(a) of the control experiment at $3 \mathrm{~h}$ shows a pattern strikingly similar to results from Fovell and Ogura (1988) and strongly indicative of crossover flow. The inflow at low levels (from right to left) is plainly evident, as is the mid-level $\theta_{\mathrm{e}}$ deficit at a height of $4 \mathrm{~km}$. At low levels, the air flows along lines of constant $\theta_{\mathrm{e}}$, but when the inflow encounters the cold pool and begins to rise, it begins to cross isopleths of $\theta_{\mathrm{e}}$. This thermodynamic pattern, where $\theta_{\mathrm{e}}$ is not conserved 


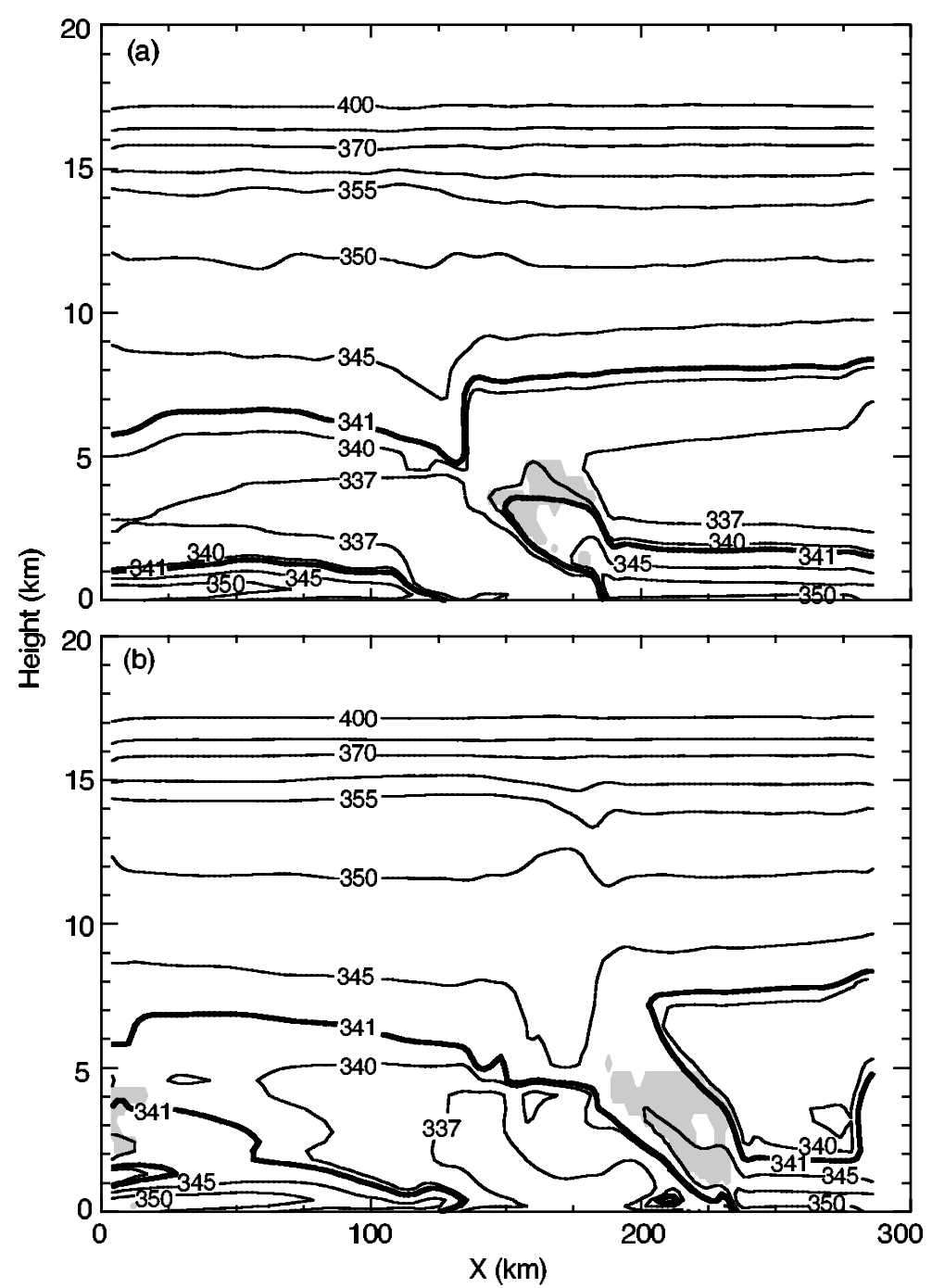

Figure 18. Vertical cross-sections of equivalent potential temperature $(\mathrm{K})$ taken through the lines indicated on Figs. 7 and 15: (a) 14 December control experiment and (b) 14 December enhanced mid-level moisture experiment. Shaded regions are moist absolutely unstable layers, as defined by Bryan and Fritsch (2000).

in the front-to-rear flow, is a strong characteristic of the crossover zone. In addition, this region of flow normal to the $\theta_{\mathrm{e}}$ isopleths is associated in the model with a strong positive correlation of vertical velocity and $\theta_{\mathrm{e}}$, another strong indication of crossover zone 'mixing.'

A similar cross-section through the enhanced-moisture domain shows significant differences (Fig. 18(b)). The $\theta_{\mathrm{e}}$ isopleths indicate that the thermodynamic character of the inflow channel is rather well maintained as it rises above the cold pool. Vertical velocity and $\theta_{\mathrm{e}}$ are correlated as in the control case, which indicates that overturning of the environment is still taking place. It appears, though, that whereas the form of the overturning in the control experiment is a typical crossover zone, the physical manifestation of the overturning in the enhanced-moisture case is a deep-layer inflow. 
Bryan and Fritsch (2000) observed layer inflows into mid-latitude MCSs and conceived of a thermodynamic state that could explain the long-term existence of this absolutely unstable state. They use the term 'MAUL' (moist absolutely unstable layer) to indicate a saturated layer in which the lapse rate is greater than the saturated lapse rate. They applied these conditions to rawinsonde and model data to show that MAUL regions were well correlated with deep-layer inflow. The grey regions in Fig. 18 are zones where the environment was analysed to satisfy MAUL criteria. The size of the MAUL in the enhanced-moisture case is significantly larger than that in the control case, which exhibits MAUL conditions near cloud base only. The large MAUL region in the enhanced-moisture experiment lies near the centre of the inflow channel and is very similar in size and shape to those found by Bryan and Fritsch. Although not shown, the cross-section for the 23 December case resembles the 14 December enhanced-moisture case, including a deep ascending inflow channel and a significant MAUL. Figure 19 shows time-height cross-sections for the three cases to indicate a lower bound on the lifetime of the simulated MAUL. For the layer-mode cases, the structure and time-scale are also similar to those of Bryan and Fritsch, with MAUL conditions typically lasting between 20 and 40 minutes at fixed locations. Figure 19(c) bears a particularly close resemblance to Fig. 17 of Bryan and Fritsch (2000).

\section{(d) Possible mechanisms that could bring about the layer mode}

The experiments have shown a tendency for layer overturning, as identified by trajectory analysis, to be correlated with mid-level environmental humidity. We briefly suggest three possible mechanisms that might bring about the layer mode of MCS inflow: two speculative external factors pertaining to the creation of enhanced mid-level humidity, and one factor internal to the simulated MCS arising from enhanced moisture.

Moistening and cooling of the upper part of a subsaturated environmental inflow layer would reduce the static stability of the inflowing layer of air, enabling the gust front to produce more lifting for a given amount of work. The closer to saturation the air becomes, the more immediately relevant the value of moist static stability. When a layer of air is near saturated and moist neutral it is easily lifted by a cold pool. The question arises how the inflow layer could become nearly saturated and moist neutral in the case of convection over the warm pool. Two possibilities are suggested.

One proposed mechanism that could produce a moistened lower tropospheric layer with a moist adiabatic lapse rate is mixing by cumulus congestus or cumulonimbus of moderate depth. Johnson et al. (1999) and Mapes (2001) present evidence from TOGA COARE that vertical mixing by such clouds has a measurable impact on the large-scale thermodynamic stratification of the atmosphere over the warm pool. If the layer of air approaching an organized MCS passes through the field of moderate convection, the humidity of the layer would be raised by upward eddy transport of humidity from near the ocean surface. In addition, moderate convection would homogenize the $\theta_{\mathrm{e}}$ in the inflow layer.

A second method for producing a nearly saturated moist neutral inflow layer is more complicated but plausible. The inflow layer might moisten by passing through a pre-existing region of stratiform precipitation. Houze and Rappaport (1984) described a tropical oceanic MCS in which the inflow to the convective region passed under a precipitating portion of the anvil of the system. Thus, the cloud system itself modified the environmental inflow. It is also conceivable that the environmental inflow could pass under the precipitating anvils of other mesoscale systems in the neighbourhood of the MCS in question. As the warm pool becomes populated by numerous MCSs during the westerly onset and westerly wind-burst periods, this scenario becomes more likely. 

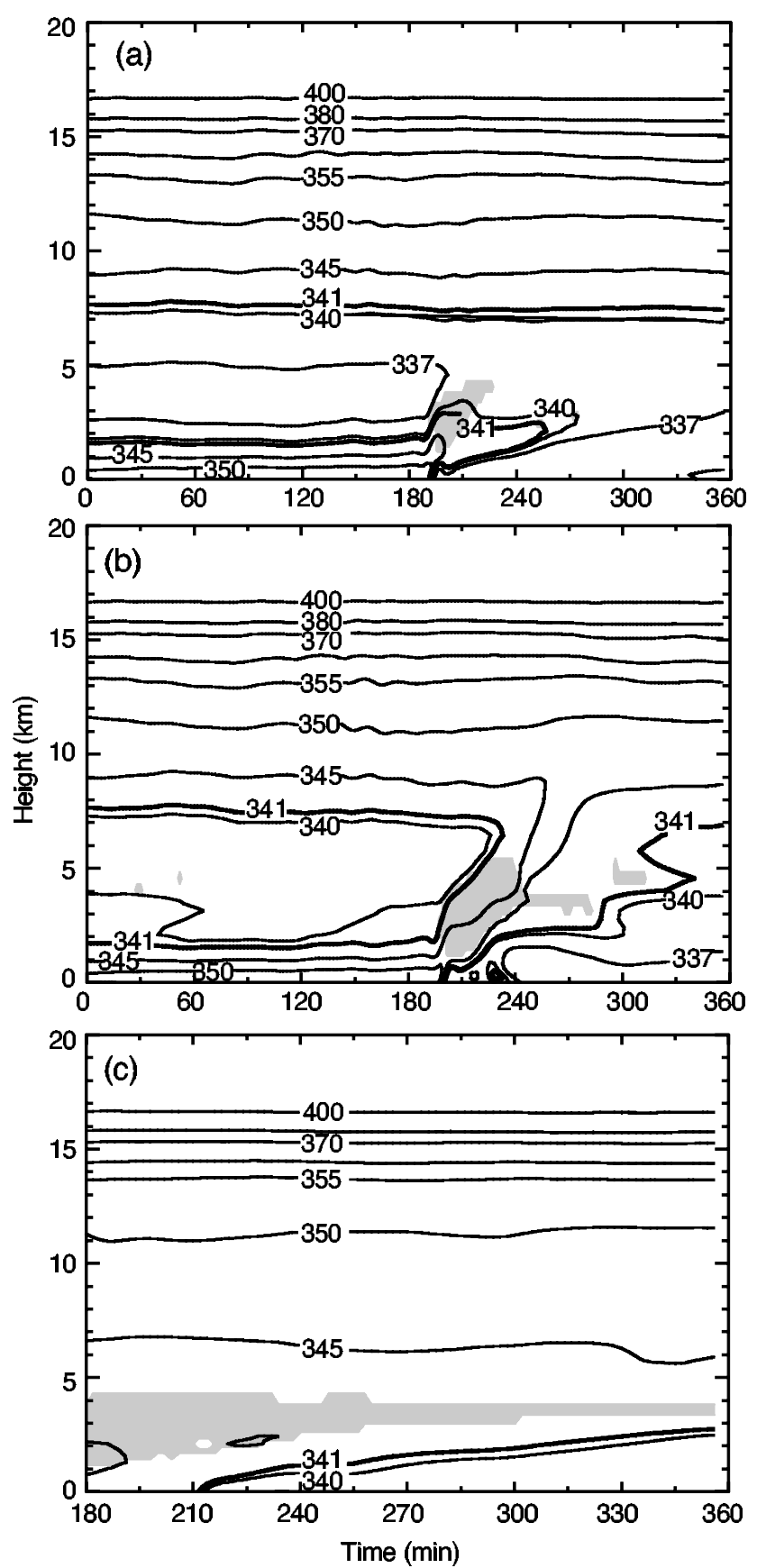

Figure 19. Time-height cross-sections of equivalent potential temperature (K) from a location in the low-level inflow region: (a) 14 December control experiment and (b) 14 December enhanced-moisture experiment. The point chosen for the 14 December runs was located at $x=198 \mathrm{~km}, y=148 \mathrm{~km}$ on Figs. 7 and 15. (c) 23 December experiment, the point located at $x=148 \mathrm{~km}, y=122 \mathrm{~km}$ on Fig. 3. Regions satisfying MAUL criteria (see text) are shaded. 
(a) $t=3 h$

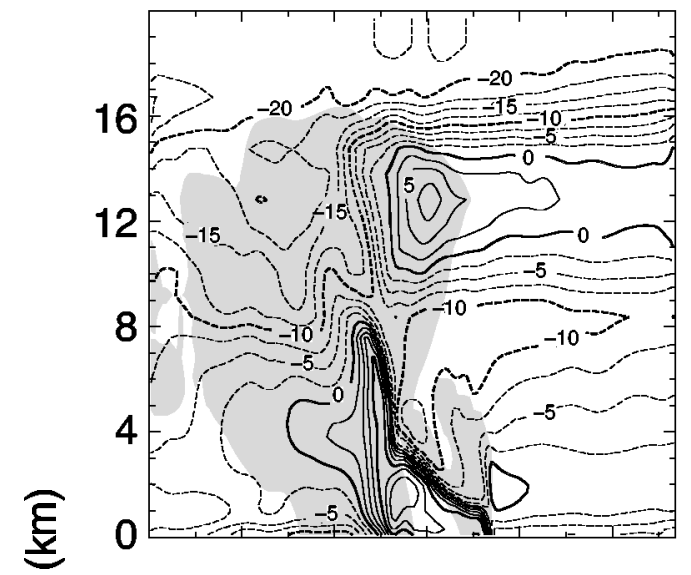

(b) $\mathrm{t}=3 \mathrm{~h}$

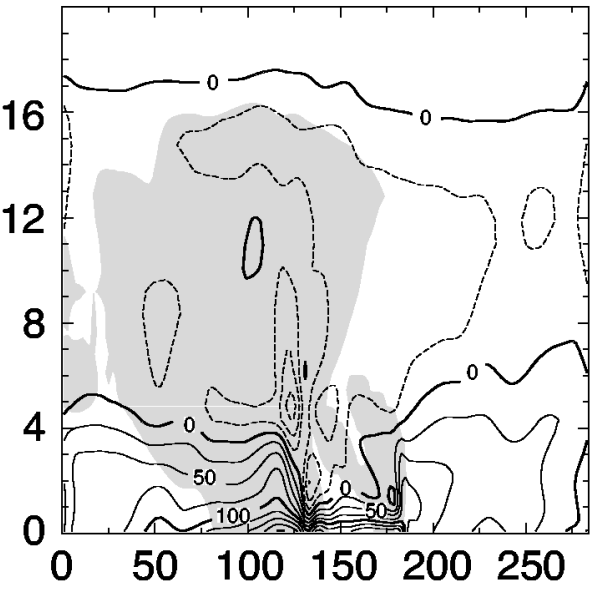

(c) $t=4 h$

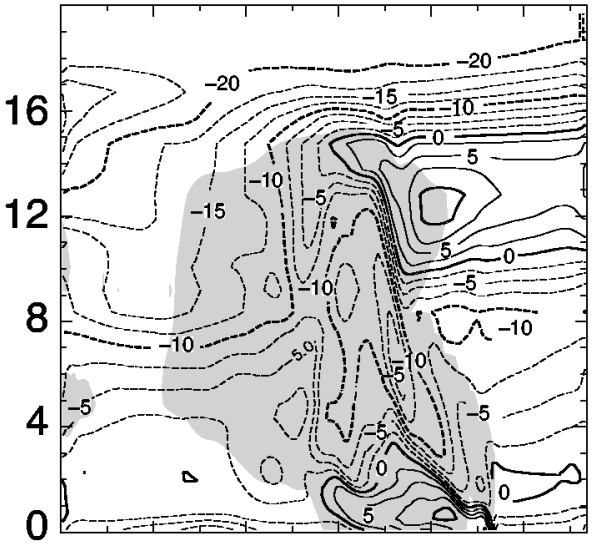

(d) $\mathrm{t}=4 \mathrm{~h}$

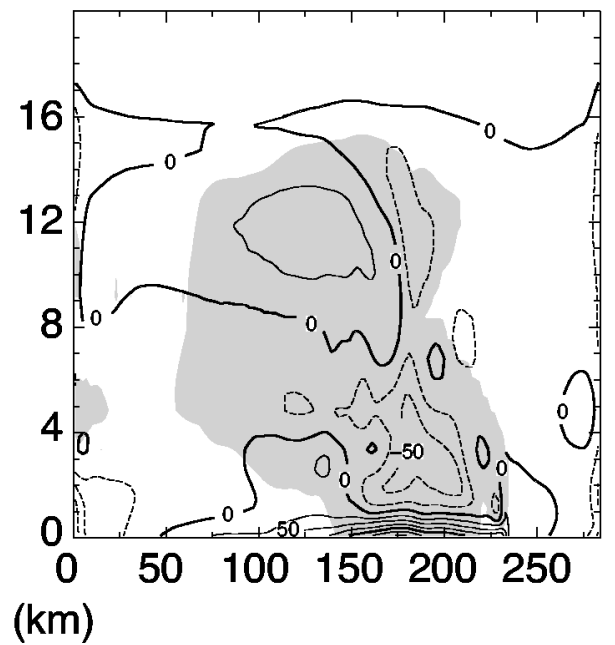

Figure 20. Vertical cross-sections for the 14 December 1992 control and enhanced mid-level moisture experiments, taken along the same line as the cross-sections in Figs. 7 and 15. (a) and (b) System-relative inflow (u) overlaid on the shaded total hydrometeor field (ice + liquid) at $3 \mathrm{~h}$. Contour interval is $2.5 \mathrm{~m} \mathrm{~s}^{-1}$. (c) and (d) Perturbation pressure field overlaid on the shaded hydrometeor field at $4 \mathrm{~h}$. Contour interval is $25 \mathrm{~Pa}$. Different times correspond to a similar stage of the convective life cycle. Negative values are shown dashed.

Moistening and cooling by precipitation particles falling from an anvil into the upper part of a subsaturated inflow layer would reduce the static stability of the inflowing layer of air. Melting and evaporation of the precipitation particles would cool and moisten the layer of inflow air. Subsidence below the anvil cloud base would largely compensate for the evaporative cooling, so the net effect on the dry static stability could be quite small. This mechanism by itself would leave $\theta_{\mathrm{e}}$ unchanged.

Since tropical oceanic convection typically exists in log-normal populations in which a few large precipitating cloud systems are accompanied by numerous middlesized and small convective clouds (Lopez 1976, 1977; Houze and Cheng 1977; and others), it seems plausible that the two mechanisms for moistening the environment could work in concert. 
The model pressure perturbation and momentum fields suggest another aspect of the effect of the moistened inflow layer on whether layer or parcel lifting occurs. This process is internal to the MCS. Perturbation pressure is calculated relative to the horizontal mean at the initial time. This is reasonable, since the initial horizontal variability is much less than that later in the simulation. System-relative $u$-velocity is calculated by subtracting the propagation speed from the total $u$-field. Weaker evaporative cooling in the cases of high mid-level humidity is evident in the perturbation pressure field, which appears to modulate in some manner the slope of the inflow layer. The slope of the inflow for the 14 December sensitivity experiment is $3-4^{\circ}$, a value in excellent agreement with the system observed on that day (Kingsmill and Houze 1999), while the slope is steeper in the control case. The amount of evaporation affects the strength of the cold pool, as reflected in the pressure perturbation field. The positive perturbation associated with the cold pool is both more intense and deeper in the control case where more evaporation occurs (Fig. 20). The pressure gradient associated with the cold pool at the surface and with the hydrostatic low above the cold pool is associated with the sloping descending rear-inflow regions visible in the plots of zonal velocity. A deep layer of air entering the system in the enhanced-moisture run appears to be rising, whereas for the control case, inflow air attempts to ascend but seems partially 'blocked' by the system rear inflow that steeply descends. We acknowledge that plots of storm-relative zonal velocity are not completely reliable as indicators of whether inflow obeys the parcel or layer flow models, but the plots qualitatively agree with the trajectory calculations in showing that increasing the mid-level relative humidity tends to have a significant impact on the character of the inflow. Because of the relationship between pressure (i.e. buoyancy) and momentum, a detailed forcing analysis would have to be performed to determine the root cause of the airflow slope. The implication of the more gradually sloping cold pool is that the mesoscale circulation takes on a greater share of the overturning of the atmosphere, when the mid-level environment is moistened. That is, the conversion of potential energy by the layer lifting may be a more efficient mechanism than the parcel lifting that is made possible when the environment is moistened.

\section{CONCLUSIONS}

The frequently employed parcel model of tropical convection does not always apply well to tropical convection. The parcel model envisages high $-\theta_{\mathrm{e}}$ air ascending from near the surface of the earth to great heights in entraining convective-scale bubbles or plumes. Air from just above the planetary boundary layer (PBL), with lower $\theta_{\mathrm{e}}$, mixes into convective downdraughts and sinks. The 'crossover zone' (Zipser 1977) embodies this concept in the dynamics of an individual mesoscale system. This pure parcel view of convection does not always agree with Doppler-radar data, which show that organized deep convective systems over the western tropical Pacific warm pool often have layers of ascending inflow $\sim 0.5-4 \mathrm{~km}$ in depth (Kingsmill and Houze 1999). Bryan and Fritsch (2000) have pointed out similar layer lifting in mid-latitude MCSs.

Trajectory analysis of the cloud-model output gives insight into when and where parcel and layer lifting occur in convection, characteristic of the type that occurs over the western Pacific warm pool. The model simulation of a convective system occurring in an environment containing numerous preceding, pre-existing, and concurrently developing MCSs (TOGA COARE 23 December case with unmodified environment) showed moistened air flowing into the mesoscale updraught in a pronounced layer-lifting configuration. In a control run occurring under westerly onset conditions (TOGA COARE 14 December case with unmodified environment), parcel convection prevails in 
the strong updraughts, and crossover-zone-like mixing occurs. Only the air in the lower part of the inflow actually rises in the deep convective updraughts of the MCS. One major difference between these two simulations is a lack of a deep, moist layer in the 14 December environment. In order to investigate the effect of mid-level moisture on the nature of inflow, the environmental humidity was increased in the 14 December case to $95 \%$ over a significant depth. Model trajectory statistics for this experiment (TOGA COARE 14 December case with moistened environment) indicate that layer lifting better describes the convective updraughts.

The model calculations suggest that a moist mid-level layer is critical to the development of the layer-lifting mode of inflow. We find this moist mid-level layer to be highly consistent with the results of Bryan and Fritsch (2000) in their study of mid-latitude MCSs (Figs. 19 and 20). We have suggested two ways that this moistening might arise. In the first hypothesized mechanism, inflow air undergoes vertical mixing by moderate cumulus and cumulonimbus (Johnson et al. 1999) before entering the updraught of the system. In the second mechanism, the evaporation of pre-existing stratiform rain occurs in concert with stratiform subsidence. Either of these processes can produce a moistened, nearly neutral, or slightly moist unstable inflow layer. Moreover, the two processes probably often act in concert. Regardless of the exact mechanism responsible for the moistening, the increased humidity and nearly moist adiabatic lapse rate imply that when the inflow layer meets the cold pool it quickly reaches saturation and the relevant static stability becomes the moist static stability. Then the inflow layer responds to the lifting by the leading edge of the cold pool as a nearly moist neutral layer, easily lifted over it. In addition, the moistened environment leads to a cold pool that is less steep (section 5(d)). This change makes it easier for the inflow air to ascend over the cold pool than when the cold pool has a steep leading edge. Thus, the moistened environment leads in multiple ways to a configuration in which the layer rather than parcel lifting becomes an efficient contributor to the overturning of unstable air.

When the MCS takes on the layer mode, favoured by a mid-level moist environment, the transports of mass, heat, and momentum by the convective system take on a different profile than in the case of parcel lifting. The air rising to upper levels comes from a layer that includes, but extends much higher than, the PBL. Observations show that much of the convective overturning of the tropical atmosphere over the warm pool (and probably elsewhere in the tropics) occurs in this layer mode (Kingsmill and Houze 1999). The modelling results presented here suggest that the accurate representation of this mode of convection in large-scale models will require accurate mid-level environmental relative humidity.

The behaviour of simulated convection described in this paper is another indication of the disparity between the mesoscale nature of tropical convection and the way tropical convection is envisaged in convective parametrization schemes. While such schemes may accomplish their immediate goals within a climate, general circulation, or numerical weather-prediction model, the fact remains that real tropical convection is to a large extent mesoscale, responds to mesoscale modified environments, and feeds on a vertical layer of air including, but extending much higher than, the PBL.

\section{ACKNOWLEDGEMENTS}

Suggestions from Professor Edward Zipser and an anonymous reviewer greatly improved the logic and flow of the manuscript. Candace Gudmundson edited the manuscript and Kay Dewar provided graphics services. The staff at the Center for the Analysis and Prediction of Storms (CAPS) assisted with the ARPS model. This research 
was supported by National Science Foundation grant number NA67RJ0155 (JISAO contribution number 812), and the National Oceanic and Atmospheric Administration grant number NA67RJ0149.

Betts, A. K.

1976

Bougeault, P., Binder, P., Buzzi, A.,

Dirks, R., Houze, R.,

Kuettner, J., Smith, R. B.,

Steinacker, R., Volkert, Hans and all MAP scientists

Braun, S. A. and Houze Jr, R. A.

Bryan, G. H. and Fritsch, J. M.

Chen, S. S.

Chen, S. S., Houze Jr, R. A. and Mapes, B. E.

Davies, $\mathrm{H}$

Doty, K. G. and Perkey, D. J.

Emanuel, K. E.

Emanuel, K. E. and Raymond, D. J. 1993 (Eds.)

Fovell, R. G. and Ogura, Y.

Godfrey, J. S., Houze Jr, R. A., Johnson, R. H., Lukas, R., Redelsperger, J.-L., Sumi, A. and Weller, R.

Grell, G., Dudhia, J. and Stauffer, D. R.

Harrison, D. E. and Giese, B. S.

Houze Jr, R. A.

Houze Jr, R. A. and Cheng, C.-P.

Houze Jr, R. A. and Rappaport, E. N.

Houze Jr, R. A., Chen, S. S., Kingsmill, D. E., Serra, Y. and Yuter, S. E.

Johnson, R. H., Rickenbach, T. M., Rutledge, S. A.,

Ciesielski, P. E. and

Schubert, W. H.

Kain, J. S. and Fritsch, J. M.

2001

\section{REFERENCES}

The thermodynamic transformation of the tropical subcloud layer by precipitation and downdraughts. J. Atmos. Sci., 33, 10081020

The MAP Special Observing Period. Bull. Am. Meteorol. Soc., 82, 433-462

\section{Trimodal characteristics of tropical convection. J. Climate, 12,} 2397-2418

The transition zone and secondary maximum of radar reflectivity behind a midlatitude squall line: results retrieved from Doppler radar data. J. Atmos. Sci., 51, 2733-2755

Moist absolute instability: the sixth static stability state. Bull. Am. Meteorol. Soc., 81, 1207-1230

'Convectively active and suppressed periods in TOGA COARE'. Pp. 583-586 in Preprints, 22nd conference on hurricanes and tropical meteorology, Ft. Collins, CO, USA. American Meteorological Society, Boston, USA

Multiscale variability of deep convection in relation to large-scale circulation in TOGA COARE. J. Atmos. Sci., 53, 1380-1409

Limitations of some common lateral boundary schemes used in regional NWP models. Mon. Weather Rev., 111, 1002-1012

Sensitivity of trajectory calculations to the temporal frequency of wind data. Mon. Weather Rev., 121, 387-401

Atmospheric convection. Oxford University Press, New York, USA

The representation of cumulus convection in numerical models. Meteorol. Mono. 24, No. 46, American Meteorological Society, Boston, USA

Numerical simulation of a midlatitude squall line in two dimensions. J. Atmos. Sci. 45, 3846-3879

COARE: an interim report. J. Geophys. Res., 103, Vol. 7-Special TOGA issue, 14395-14450

'A description of the fifth-generation Penn State/NCAR mesoscale model (MM5)'. NCAR Technical Notes, NCAR/TN398+STR

Episodes of surface westerly winds as observed from islands in the western tropical Pacific. J. Geophys. Res., 96, 3221-3237

Cloud dynamics. Academic Press, San Diego, USA

Stratiform precipitation in regions of convection: a meteorological paradox? Bull. Am. Meteorol. Soc., 78, 2179-2196

Radar characteristics of tropical convection observed during GATE: mean properties and trends over the summer season. Mon. Weather Rev., 105, 964-980

Air motions and precipitation structure of an early summer squall line over the eastern tropical Atlantic. J. Atmos. Sci., 41, $553-574$

Convection over the Pacific warm pool in relation to the atmospheric Kelvin-Rossby wave. J. Atmos. Sci., 57, 3058-3089

A one-dimensional entraining/detraining plume model and its application in convective parameterization. J. Atmos. Sci., 47, 2784-2802 
Kingsmill, D. E. and

Houze Jr, R. A.

LeMone, M. A., Barnes, G. M. and Zipser, E. J.

Lin, X. and Johnson, R. H.

Lin, Y.-L., Farley, R. D. and Orville, H. D.

Locatelli, J. D. and Hobbs, P. V.

López, R. E.

1999

1984

1996

1983

1974

1976

1977

Lucas, C. E. and Zipser, E. J.

Lucas, C., Zipser, E. J. and Ferrier, B. S.

Madden, R. and Julian, P.

Maddox, R. A.

Mapes, B. E.

Mapes, B. E. and Houze Jr, R. A.

McCumber, M., Tao, W.-K., Simpson, J., Penc, R. and Soong, S.-T.

Nakazawa, T.

Nesbitt, S. W., Zipser, E. J. and Cecil, D. J.

Potter, B. E.

Redelsperger, J.-L. and Lafore, J.-P. 1988

Rotunno, R., Klemp, J. B. and Weisman, M. L.

Rutledge, S. A. and Hobbs, P. V.

Srivastava, R. C.

1985

Trier, S. B., Skamarock, W. C., LeMone, M. A., Parsons, D. B. and Jorgensen, D. P.

Webster, P. J.

Xue, M., Droegemeier, K. K., Wong, V., Shapiro, A. and Brewster, K.

Yang, M.-J. and Houze Jr, R. A.

Young, G. S., Perugini, S. M. and Fairall, C. W.

1971

1972

1980

2001

1993

1991

1988

2000

1988

1984
Thermodynamic characteristics of air flowing into and out of precipitating convection over the west Pacific warm pool. Q. J. R. Meteorol. Soc., 125, 1209-1229

Momentum flux by lines of cumulonimbus over the tropical oceans. J. Atmos. Sci., 41, 1914-1932

Kinematic and thermodynamic characteristics of flow over the western Pacific warm pool during TOGA COARE. J. Atmos. Sci., 53, 695-715

Bulk parametrization of the snow field in a cloud model. J. Clim. Appl. Meteorol., 22, 1065-1092

Fall speeds and masses of solid precipitation particles. J. Geophys. Res., 79, 2185-2197

Radar characteristics of the cloud populations of tropical disturbances in the northwest Atlantic. Mon. Weather Rev., 104, 269-283

The lognormal distribution and cumulus cloud populations. Mon. Weather Rev., 105, 865-872

Environmental variability during TOGA COARE. J. Atmos. Sci., 57, 2333-2350

Sensitivity of tropical west Pacific oceanic squall lines to tropospheric wind and moisture profiles. J. Atmos. Sci., 57, 23512373

Detection of a 40-50 day oscillation in the zonal wind in the tropical Pacific. J. Atmos. Sci., 28, 702-708

Description of global scale circulation cells in the Tropics with a 40-50-day period. J. Atmos. Sci., 29, 1109-1123

Mesoscale convective complexes. Bull. Am. Meteorol. Soc., 61, $1374-1387$

Water's two height scales: the moist adiabat and the radiative troposphere. Q. J. R. Meteorol. Soc., 127, 2353-2366

Cloud clusters and superclusters over the oceanic warm pool. Mon. Weather Rev., 121, 1398-1415

Comparison of ice-phase microphysical parameterization schemes using numerical simulations of tropical convection. J. Appl. Meteorol., 30, 985-1004

Tropical super clusters within intraseasonal variations over the western Pacific. J. Meteorol. Soc. Japan, 66, 823-839

A census of precipitation features in the tropics using TRMM: radar, ice scattering, and lightning observations. J. Climate, 13, 4087-4106

Improvements to a commonly used cloud microphysical bulk parametrization. J. Appl. Meteorol., 30, 1040-1042

A three-dimensional simulation of a tropical squall line: convective organization and thermodynamic vertical transport. J. Atmos. Sci., 45, 1334-1356

A theory for strong, long-lived squall lines. J. Atmos. Sci., 45, $463-485$

The mesoscale and microscale structure and organization of clouds and precipitation in midlatitude cyclones. XII: A diagnostic modeling study of precipitation development in narrow, cold-frontal rainbands. J. Atmos. Sci., 41, 29492972

A simple model of an evaporatively driven downdraught application to a microburst downdraught. J. Atmos. Sci., 42, 1004 1023

Structure and evolution of the 22 February 1993 TOGA COARE squall line: numerical simulations. J. Atmos. Sci., 53, 28612886

The role of hydrological processes in ocean-atmosphere interactions. Rev. Geophys., 32, 427-476

1995 'ARPS version 4.0 user's guide'. Center for the Analysis and Prediction of Storms

Multicell squall-line structure as a manifestation of vertically trapped gravity waves. Mon. Weather Rev., 123, 641-661

1995 Convective wakes in the equatorial Pacific during TOGA. Mon. Weather Rev., 123, 110-123 
Zipser, E. J.

1969 The role of organized unsaturated convective downdraughts in the structure and rapid decay of an equatorial disturbance. J. Appl. Meteorol., 8, 799-814

1977 Mesoscale and convective-scale downdraughts as distinct components of squall-line circulation. Mon. Weather Rev., 105, 1568-1589 